\title{
Microwave-dried or air-dried? Consumers' stated preferences and attitudes for organic dried strawberries. A multi-country investigation in Europe
}

Article

Accepted Version

Creative Commons: Attribution-Noncommercial-No Derivative Works 4.0

Asioli, D., Rocha, C., Wongprawmas, R., Popa, M., Gogus, F. and Almli, V. L. (2019) Microwave-dried or air-dried? Consumers' stated preferences and attitudes for organic dried strawberries. A multi-country investigation in Europe. Food Research International, 120. pp. 763-775. ISSN 0963-9969 doi: https://doi.org/10.1016/j.foodres.2018.11.037 Available at https://centaur.reading.ac.uk/80702/

It is advisable to refer to the publisher's version if you intend to cite from the work. See Guidance on citing.

To link to this article DOI: http://dx.doi.org/10.1016/j.foodres.2018.11.037

Publisher: Elsevier

All outputs in CentAUR are protected by Intellectual Property Rights law, including copyright law. Copyright and IPR is retained by the creators or other copyright holders. Terms and conditions for use of this material are defined in the End User Agreement. 


\section{www.reading.ac.uk/centaur}

\section{CentAUR}

Central Archive at the University of Reading

Reading's research outputs online 


\section{Accepted Manuscript}

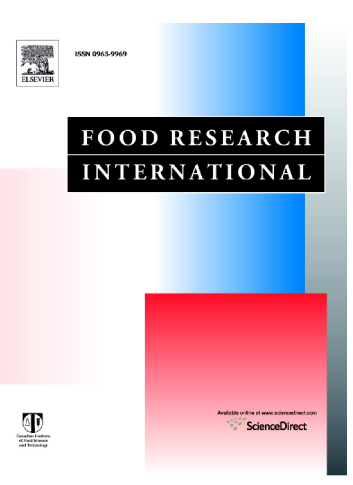

D. Asioli, C. Rocha, R. Wongprawmas, M. Popa, F. Gogus, V.L.

Microwave-dried or air-dried? Consumers' stated preferences and attitudes for organic dried strawberries. A multi-country investigation in Europe Almli

PII: $\quad$ S0963-9969(18)30922-0

DOI: $\quad$ https://doi.org/10.1016/j.foodres.2018.11.037

Reference: $\quad$ FRIN 8100

To appear in: $\quad$ Food Research International

Received date: $\quad 17$ September 2018

Revised date: $\quad 12$ November 2018

Accepted date: $\quad 16$ November 2018

Please cite this article as: D. Asioli, C. Rocha, R. Wongprawmas, M. Popa, F. Gogus, V.L. Almli , Microwave-dried or air-dried? Consumers' stated preferences and attitudes for organic dried strawberries. A multi-country investigation in Europe. Frin (2018), https://doi.org/10.1016/j.foodres.2018.11.037

This is a PDF file of an unedited manuscript that has been accepted for publication. As a service to our customers we are providing this early version of the manuscript. The manuscript will undergo copyediting, typesetting, and review of the resulting proof before it is published in its final form. Please note that during the production process errors may be discovered which could affect the content, and all legal disclaimers that apply to the journal pertain. 


\title{
Microwave-dried or Air-dried? Consumers' Stated Preferences and Attitudes for
}

\section{Organic Dried Strawberries. A Multi-Country Investigation in Europe}

\author{
Asioli, D. ${ }^{\mathrm{a}, \mathrm{b}, \mathrm{h},{ }^{*}}$, Rocha, C. ${ }^{\mathrm{c}, \mathrm{d}}$, Wongprawmas, R. ${ }^{\mathrm{e}}$, Popa, M. ${ }^{\mathrm{f}}$, Gogus, F. ${ }^{\mathrm{g}}$, Almli, V. L. ${ }^{\mathrm{b}}$ \\ ${ }^{a}$ University of Reading, United Kingdom. \\ ${ }^{\mathrm{b}}$ NOFIMA AS, Norway. \\ ${ }^{\mathrm{c}}$ University of Porto, Portugal. \\ ${ }^{\mathrm{d}}$ SenseTest Lda, Portugal. \\ ${ }^{\mathrm{e}}$ University of Bologna, Italy. \\ ${ }^{\mathrm{f} U n i v e r s i t y ~ o f ~ A g r o n o m i c a l ~ S c i e n c e s ~ a n d ~ V e t e r i n a r y ~ M e d i c i n e ~ o f ~ B u c h a r e s t, ~ R o m a n i a . ~}$ \\ ${ }^{\mathrm{g}}$ Gaziantep University, Turkey. \\ ${ }^{\mathrm{h}}$ University of Arkansas, United States.
}

*Corresponding author. 


\begin{abstract}
Non-thermal food processing technologies are becoming more important in the organic food sector because, beyond preserving the organic feature, they could offer organic products with additional benefits in terms of enhanced nutritional content and healthiness as well as better sensory properties that could satisfy the more complex demands of organic consumers. Berries have a well-known health benefits and show increasing market shares in European markets while dehydration can increase the food convenience in terms of extended shelf-life. This study investigates for the first time organic consumers' stated preferences, attitudes and individual differences for a non-thermal organic processing technology. Specifically, we investigated consumers' preferences for organic dried strawberries varying in drying technology used, such as the most conventional (i.e. thermal) air drying and the most innovative (i.e. non-thermal) microwave drying, origin, price levels, and nutrient contents in three European countries: Norway, Romania and Turkey. Data from a total of 614 consumers were collected through an online choice experiment. Results show that on average consumers prefer organic dried strawberries produced with air drying technology that have national origin, with natural nutrient content and at low price, but country and individual differences are identified. Consumers who showed least rejection for microwave dried products are young, mostly from Norway and have higher positive attitudes towards new food technologies. Consumers who showed most rejection for microwave dried products are older, mostly from Turkey and have higher positive attitudes for organic, natural and ecological products. Organic producers who adopt microwave drying might better inform consumers about the characteristics, the process and highlight the nutritional benefits of such technology. Finally, this research informs policy makers about the need to define and regulate more clearly microwave drying as an organic technology, as well as to regulate labelling to ensure that consumers are not misled and correctly informed about the new technology.
\end{abstract}


Keywords: choice experiment; organic dried strawberries; non-thermal food technologies; microwave drying; European countries; consumer preferences; consumer heterogeneity. 


\section{Introduction}

Nowadays, food consumption is increasingly affected by the three major trends of sustainability, health and convenience (Grunert, 2013). Sustainability is driven by the growing awareness of environmental effects caused by conventional agricultural practices which resulted, for example in an increasing expansion of organic agriculture and markets (Aschemann, Hamm, Naspetti, \& Zanoli, 2007). Health attitudes are driven by consumer concerns, sparked by the increasing number of food and lifestyle related diseases (e.g. diabetes and obesity) (Kearney, 2010; Weis, 2007) as well as allergies and intolerances towards some specific food products or components that drive consumers' preferences towards food products that report "clean labels" (Asioli, et al., 2017). Convenience relates to easiness of food consumption (i.e. ready meals, extended shelf-life, homedelivered food, etc.) and food producers during the last decades have responded to this consumer demand by launching on the market an increasing number of convenient food products (Lachat et al., 2012).

The European organic food market is currently one of the most rapidly expanding market $(+114 \%$ between 2006 and 2017) due to the increasing consumer demand for potentially healthier and more environmental friendly food products (FIBL, 2017; IFOAM, 2015). In 2015 the market has been of 352 million Euros in Norway, 80 million Euros in Romania and 4 million Euros in Turkey (FIBL, 2017). However, organic consumers are not only looking for the 'organic' feature itself, which is perceived to benefit the environment and their health, but also increasingly demand convenient organic processed foods, for instance ready-to-eat food products, and products of extended shelf-life (Kretzschmar \& Schmid, 2011). According to the guidelines stated on the EU regulations 834/2007 (European Commission, 2007) and 848/2018 (European Commission, 2018), organic processing methods should guarantee genuineness, authenticity and preservation of the natural properties of the raw materials and also follow the three principles: freshness, minimal processing, and careful treatment (Kahl et al., 2012). 
From a balanced nutritional diet and healthiness point of view, fruits have a good image (Briz et al., 2008) and play a key role in the prevention of chronic disease and premature death (WHO, 2003). Among the different fruit species, berries are known to be rich in vitamins, fibre, antioxidants, polyphenols and minerals that consumers appreciate for a healthy diet (Schnettler et al., 2011). The presence of these nutritional compounds in the diet is suggested to potentially reduce the risk of cardiovascular disease, inflammation, obesity, diabetes, cancer and other chronic diseases (Jia, Kong, Liu, Diao, \& Xia, 2012; Szajdek \& Borowska, 2008; Wu, Frei, Kennedy, \& Zhao, 2010). Among the different types of berries available on the market, strawberries are of particular interest because with raspberries they dominate the berries market both in terms of value and volume (Invenire Market Intelligence, 2008). In addition, strawberries due to their valuable sensory (i.e. appearance and flavour) (Aday \& Caner, 2014; Tanase et al., 2016) and nutritional properties (i.e. richness in vitamins, phenolic compounds and anthocianins) (Basu, Nguyen, Betts, \& Lyons, 2014) are highly appreciated by consumers (Häkkinen \& Törrönen, 2000; Meyers, Watkins, Pritts, \& Liu, 2003). However, one of the barriers to the consumption of fresh berries, is that they are highly perishable as they have relatively high physiological activity after harvest. This leads to a rapid deterioration of quality characteristics due to softening, shrinkage, discoloration, development of off-flavours and finally fungal decay, resulting in a short shelf-life (Wang \& Gao, 2013; Wang et al., 2014). Indeed, if healthiness is one of the key motive that drives fruit consumption, the main barriers are represented by the perception of price, quality and convenience (Harker et al., 2003).

Drying is a very well-known and ancient food technology able to preserve food products (Moses, Norton, Alagusundaram, \& Tiwari, 2014; Zielinska \& Michalska, 2016). The dehydration process offers a better preservation of nutritional compounds of food products, extends shelf-life and reduces packaging, storage, handling and transportation costs; in addition, it offers the possibility of out-of-season availability (Orsat, Changrue, \& Raghavan, 2006; Zielinska \& Michalska, 2016). 
Technically, drying reduces the moisture content within food products and it is mainly used for food products with high moisture content $(>80 \%)$ such as fruits, vegetables and other food products considered highly perishable (Orsat et al., 2006). In a study of Jesionkowska, Sijtsema, Konopacka, \& Symoneaux (2009), the interest of consumers in dried fruits was related to the high content of antioxidants in this type of food. Conventional drying technologies such as hot air and combustion gases use the heat as transfer medium (i.e. thermal technologies) (Zarein, Samadi, \& Ghobadian, 2015). However, these technologies suffer from two major drawbacks, namely the large loss in nutritional, functional and sensory properties of treated fruit and vegetables (Aguilera, Chiralt, \& Fito, 2003; Moses, Paramasivan, R, \& Kumar, 2013; Vadivambal \& Jayas, 2007) and the high energy consumption (Raghavan et al., 2005). Due to these limitations, during the last decades nonthermal (also called "mild" or "minimal") food technologies are gaining importance due to increased consumer demand for food processing technologies that have a reduced impact on nutritional content and overall food quality (i.e. largely retaining their nutritional qualities and better sensory characteristics) (Awsi, Monika, SA, \& Tsering, 2017; Fellows, 2017). Examples of non-thermal food technologies are high hydrostatic pressures (HPP), ionising radiation, pulsed electric fields (PEF), pulsed light and UV light and ultrasound (Fellows, 2017). Specifically for drying technologies, due to the limitations of the conventional thermal air drying technology, significant advancements have been made in the recent years in terms of drying techniques (see Moses et al. 2014, for a review), pre-treatment and equipment (Dev \& Raghavan, 2012) able to offer dried new products of higher quality features (Zielinska \& Michalska, 2016). Microwave (MW) drying is a non-thermal technology that involves heating and mass-transfer where vapour is generated inside a food item and then spread through internal pressure gradient (Guo, Sun, Cheng, \& Han, 2017; Wray \& Ramaswamy, 2015). More specifically, MW drying translates the high frequency electromagnetic energy into heat, such that liquid moisture contained within the food item is intensively evaporated and transported toward the food material surface ( $\mathrm{Li}$, Wang, \& Kudra, 2011). MW drying is suitable as an organic processing technology because it is a careful and 
minimal processing treatment. It is able to preserve a larger quantity of natural bioactive compounds, it better preserves sensory properties (Guo et al., 2017), it requires less energy consumption (Chandrasekaran, Ramanathan, \& Basak, 2013; Guo et al., 2017; Moses et al., 2014), and it is also less time-consuming than the traditional air-drying process (Wojdyło, Figiel, \& Oszmiański, 2009; Zhang, Tang, Mujumdar, \& Wang, 2006). In particular, MW drying allows to retain large quantities of phenolic compounds, anthocianins and antioxidant capacity compared to the conventional hot air convective drying and has been successfully used for dehydration of cranberries (Wojdyło, Figiel, Lech, Nowicka, \& Oszmiański, 2014) and blueberries (Zielinska, Sadowski, \& Blaszczak, 2015; Zielinska \& Markowski, 2016). However, since the implementation of MW drying technology is expensive and challenging (e.g. non-uniform heating that results in the formation of hot/cold spots in the course of heating) (Chizoba Ekezie, Sun, Han, \& Cheng, 2017; Dehghannya, Hosseinlar, \& Heshmati, 2018; Moses et al., 2014), research should be conducted to investigate organic consumers' preferences for berry products treated with MW drying to better understand their preferences. In addition, the introduction of new food technologies, as MW drying, is at high risk since consumers might be suspicious with high risks of product rejections as literature report for new food technologies (Giordano, Clodoveo, Gennaro, \& Corbo, 2018; Lusk, Roosen, \& Bieberstein, 2014; Siegrist, 2008a). This is linked with the increased consumer interest for food product technology (Grunert, Bredahl, \& Scholderer, 2003) and thus it is important to investigate consumer attitudes towards new food technology at an early stage of product development (Siegrist, 2008b; Van Kleef, Van Trijp, \& Luning, 2005). Therefore there is a need to get information from organic consumers' side to evaluate reactions towards this new non-thermal processing technology and ensure a successful introduction to market. To the authors' knowledge, there is no previous study in the literature that investigates consumers' preferences and attitudes for organic dried berries treated with MW drying. 
This study uses an online choice experiment (CE) to investigate consumers' stated preferences, attitudes and individual differences for organic dried strawberries varying in drying technology, nutrient level, origin and price in three diverging European cultures: Norway, Romania and Turkey. The main objectives of this research are: (i) to investigate consumers' preferences for organic dried strawberries focusing on two drying processing technologies (i.e. air drying and MW) and compare across the different countries; (ii) to investigate individual technology preferences and characterize consumer profiles in terms of attitudes, habits and socio-demographics across the different countries investigated.

We decided to focus on the individual technology preferences because to support market research it is essential to understand consumer segments that might react differently to a new technology introduction (Evans, Kermarrec, Sable, \& Cox, 2010; Salgado-Beltrán, Beltrán-Morales, VelardeMendivil, \& Robles-Baldenegro, 2018; Siegrist, 2008b).

\section{MATERIALS AND METHODS}

This methodological section introduces the choice experiment method, the chosen product attributes and levels, the experimental choice design and procedure, the consumer attributes investigated as well as the data analysis approaches.

\subsection{The choice experiment method}

Choice experiment (CE) is one of the most popular stated multi-attributes valuation method used to investigate consumers' preferences and willingness to pay (WTP) for market and non-market goods and services (Asioli, Næs, Øvrum, \& Almli, 2016; Hensher, Rose, \& Green, 2015; Jaeger \& Rose, 2008; Lusk \& Schroeder, 2004; Scarpa \& Del Giudice, 2004; Van Loo, Caputo, Nayga, \& Verbeke, 2014; Van Wezemael, Caputo, Nayga, Chryssochoidis, \& Verbeke, 2014). CEs are based on the Random Utility Theory (RUT) (Thurstone, 1927) and Lancaster's consumer demand theory (Lancaster, 1966), implying that subjects derive utility from attributes of a good rather than from 
the good itself. In a CE framework, consumers are presented with a series of alternative choice scenarios and are asked to choose their most preferred option within each choice scenario (Almli \& Naes, 2018; Louviere et al., 2000). The different alternatives are composed of different combinations of attribute levels which characterize the goods based on an experimental design (Hensher et al., 2015; Louviere et al., 2000).

\subsection{Product attributes and levels}

Due to the difficulty in finding real suitable dried strawberry products for the countries investigated, we chose to conduct an online CE. Thus, based on an experimental choice design we created a series of mock-up product images of dried strawberry packages varying in four attributes: origin, drying technology, nutrient content and price (Table 1).

\section{Table 1 - Attribute levels used in the study}

We included origin because previous studies show that it is one of the most important attributes that consumers take into account when purchasing strawberry products (Bhat, Geppert, Funken, \& Stamminger, 2015; Hinson \& Bruchhaus, 2008; Panico, Del Giudice, Cicia, \& Cembalo, 2011). In addition, given the fact that in many countries the demand of organic food is growing much faster than domestic production, the supply of foreign organic products is increasingly getting importance thus getting information about organic consumers' preferences for different products origins is relevant for organic producers for better targeting their marketing and business strategies and enrich the lack of research (Thøgersen, Pedersen, Paternoga, Schwendel, \& Aschemann-Witzel, 2017). The technology attribute was used to test two drying technologies: the most conventional air drying and the most innovative non-thermal MW drying. While air drying is the most used technology to dry berries products, MW drying is particularly interesting because it better preserves natural nutritional content. The nutrient content attribute was selected based on the fact that it is one of the 
main attributes that consumers take into account as criteria of purchasing organic foods (Bourn \& Prescott, 2002) and berries (Farruggia, Crescimanno, Galati, \& Tinervia, 2016; Tanase et al., 2016), and that the two technologies investigated have different effects on the natural nutrient content of the final product, where MW drying retains more natural nutrients than air drying technology. However, in order to distinguish whether consumer choices would be rather driven by technology or by nutrient content, we kept these two factors independent from each other in our factorial design. Finally, three price levels were tested varying from $-10 \%$ to $+10 \%$ of the average market prices in each target country for a $40 \mathrm{~g}$ package of dried strawberries, which is a typical size of selling. We used price percentage differences to be able to compare the three target countries in spite of differing mean market prices and currencies. The mean price levels were selected by researching the dried strawberries prices in different Norwegian, Romanian and Turkey stores where dried strawberries are typically sold. All conjoint attributes were integrated in the form of text or symbols in the mock-up package images. In addition, all packages included an organic logo (i.e. either EU or national logos depending on the product's origin in the factorial design), see Figure 1 for example packages.

To make sure that respondents would be aware of all four conjoint attributes, an introduction screen showed an example product profile where arrows pointed at the relevant texts and symbols on the package. This technique has been recommended to help counterbalance possible inequalities in visual salience linked to the specific usage of colors and font size for the different attributes (Almli \& Naes, 2018).

\section{Figure 1 - An example of choice set (English translation)}

\subsection{Choice experiment design}

We used a D-optimal design for the choice experiment, using the software Ngene 1.1.1 (Choice Metrics, 2012). This design allows parameters to be estimated with the lowest possible number of 
asymptotic standard errors in the parameter estimates (i.e. the square roots of the diagonal elements of the asymptotic variance-covariance) (Jaeger \& Rose, 2008). The design was based on 11 choice scenarios (i.e. choice sets) always offering two organic dried strawberry alternatives (called options "A" and "B") and an "opt-out" or no purchase option (called option "C") (Figure 1). The chosen design was the one which had the lowest D-error (0.63) among the designs.

\subsection{Consumer attributes}

In order to characterise consumer profiles related to different individual choice preferences, a number of consumer attributes were collected. These attributes include: (i) berry consumption habits (location of purchasing and purchasing frequency), (ii) dried fruits/berries consumption habits (importance of attributes for purchasing and location of consumption), (iii) attitudes to health and natural product interest using the items from the Health and Taste Attitude Questionnaire (HTAQ) (Roininen, Lähteenmäki, \& Tuorila, 1999), (iv) attitudes to organic and ecological food using the items from the Food Related Lifestyle (FRL) model (Bruns $\varnothing$ \& Grunert, 1995) and, (v) food technology neophobia using the Food Technology Neophobia Scale (FTNS) (Cox \& Evans, 2008). Finally, we collected a number of socio-demographic attributes. Consumer attributes were measured using both numerical and categorical variables. For the importance of attributes for choosing dried fruit/berries, the scale was anchored from 1 (Very unimportant) to 7 (Very important). Consumers' attitudes were collected using scales anchored form (Strongly disagree) to 7 (Strongly agree). For the data analysis, all the categorical attributes have been coded using dummy variables where 0 represents the absence of the actual level while 1 represents the presence of the attribute level. The complete questionnaire is available upon request.

\subsection{Data collection}

A hypothetical web-based survey was carried out in Norway, Romania and Turkey. This type of web-procedure has been used in different research studies due to the low cost and time effectiveness 
to gather the answers. The information obtained through web-surveys and in-person surveys has been reported to be similar (Canavari, Nocella, \& Scarpa, 2005). The company Userneeds (Copenhagen, Denmark) was responsible for the recruitment task and for the web-survey implementation. We recruited only consumers aged between 18 and 65 years, who like strawberries, purchase organic foods (at least once a month), as well as purchase and consume dried nuts, fruits and/or berries (at least once during the last three months). An overall sample of 13,070 consumers were invited by e-mail to participate to the web-survey, and of them 614 consumers $(4.7 \%$ of the invited consumers) fulfilled the eligibility criteria and completed the survey. Note that the survey was closed once our target of minimum 200 consumers per country was reached. The questionnaire comprised an initial information screen, then (i) recruitment questions (in case of failure of selection criteria the respondents were not allowed to continue answering), (ii) choice tasks, (iii) consumer attributes questionnaire.

The survey development was executed in English, then translated in Norwegian, Romanian and Turkish by the local research teams, then carefully checked again against the English questionnaire. The global survey was pretested by 6 to 19 respondents (colleagues of the local teams) in each country. After adjustments, it was then pilot-tested ( $n=20$ per country), before the full data collection took place in February 2017.

\subsection{Data analysis}

\subsubsection{Descriptive statistics}

Consumer attributes were analyzed using statistical descriptive analysis, such as frequency and mean. Significant differences among the countries were tested with non-parametric Kruskall-Wallis and Dunn tests for ordinal and Chi-Squared test for nominal variables. Cronbach's alpha was calculated for checking the internal consistency of attitudinal questionnaires. STATA 15.0 software (StataCorp LP, College Station, US) was used for the analyses. 


\subsubsection{Mixed Logit Model}

Choice-based data are routinely analysed within a random utility framework by so-called discrete choice models (DCMs) (Louviere et al., 2000; Train, 2009). The approach consists in modelling "Utility", that is to say the net benefit a consumer obtains from selecting a specific product in a choice situation, as a function of the conjoint factors. The utility of a product $j$ for individual $m$ in a choice occasion $t$ is written:

$$
U_{m j t}=\boldsymbol{\beta}_{m}{ }_{m} \mathbf{x}_{m j t}+\varepsilon_{m j t}
$$

where $\boldsymbol{\beta}_{m}$ is a vector of individual-specific parameters accounting for preference heterogeneity, $\mathbf{x}_{m j t}$ is a vector of conjoint factors, and $\varepsilon_{m j t}$ is a random error term.

Among different DCMs, Mixed Logit (ML) models are widely applied due to their flexibility (Train, 2009) and since they allow models that may better match real-world situations. ML models have increased in usage within sensory and consumer science in recent years in parallel with the usage of choice and ranking approaches (Almli, Øvrum, Hersleth, Almøy, \& Næs, 2015; Jaeger \& Rose, 2008; Zhou, Hu, \& Huang, 2016).

The main specification of the model included main effects and interactions of the conjoint variables for Origin, Technology, Nutrition content and Price. All variables were coded using effects coding $(-1 ; 1)$ (Bech \& Gyrd-Hansen, 2005), except price which was coded in three levels expressing the percentage deviations from the mean price $(-10 ; 0 ;+10)$. The variables were coded as presented in Table 1.

The utility ML model for dried strawberries $j$ for individual $i$ in choice occasion $t$ is written:

$$
\begin{aligned}
U_{i j t}= & \beta_{1 i} \text { Origin }_{i j t}+\beta_{2 i} \text { Technology }_{i j t}+\beta_{3 i} \text { Nutrition }_{i j t}+\beta_{4 i} \text { Price }_{i j t}+B_{5 i}\left(\text { Origin }^{*} \text { Technology }\right)_{i j t}+ \\
& \beta_{6 i}\left(\text { Origin }^{*} \text { Nutrition }\right)_{i j t}+\beta_{7 i}\left(\text { Origin }^{*} \text { Price }\right)_{i j t}+\beta_{8 i}(\text { Technology } * \text { Nutrition })_{i j t}+ \\
& \beta_{9 i}(\text { Technology*Price })_{i j t}+\beta_{10 i}(\text { Nutrition } * \text { Price })_{i j t}+\varepsilon_{i j t}
\end{aligned}
$$


The interaction effects are obtained by multiplying the columns in the data set for the corresponding main effects. The consumer effect is automatically incorporated here since all coefficients are considered random. The ML model used here assumes random parameters with normal distributions for all conjoint factors, consumer characteristics and two-way interactions. These random coefficients are further assumed to be independent. This model provides estimates of the mean and the standard deviation of the random conjoint parameters for main effects and their interactions. The ML model was estimated using the Stata module mixlogit (Hole, 2007) run in STATA 15.0 software (StataCorp LP, College Station, US). Two thousand Halton draws were used in the simulations. More details on estimation of ML models are found in Train (2009) and Hole (2007).

\subsubsection{Principal Component Analysis (PCA)}

The matrix of individual parameter estimates $\hat{\boldsymbol{\beta}}_{m}$, extracted from the ML model (Eq. 3) by using the command mixlbeta in STATA, is submitted to Principal Component Analysis (PCA) in order to identify the main drivers of variation between individual choices. PCA was conducted in the multivariate statistical software package The Unscrambler X 10.4.1 (Camo Software AS, Norway).

\subsubsection{Partial Least Squares Regression (PLSR)}

Cross-national and country-specific models were conducted with Partial Least Squares Regression (PLSR) by relating the individual parameter estimates $\hat{\boldsymbol{\beta}}_{m}$ for technology (Ys) (i.e. dependent variable) to the consumer attributes (i.e. independent variables). A similar approach has previously been used by Asioli, Almli, \& Næs (2016) and Endrizzi, Menichelli, Johansen, Olsen, \& Næs (2011). We used a several-step procedure: to start with we included in the model all the consumer attributes (Xs) investigated to check which ones were significantly related to technology preferences. Then, several refined models were run successively by selecting as consumer attributes (Xs) only the significant ones from the former step. Such variable selection was repeated until 
stability in the significant consumer attributes was reached, to achieve model reduction and better visualisation of results. Interpretations are based on the final refined model only. In all models we used standardized X-variables, cross-validation with 20 random segments and significance testing by jack-knifing at 5\% significance level (Martens \& Martens, 2000) in The Unscrambler X 10.4.1 (Camo Software AS, Norway).

\section{RESULTS}

\subsection{Characteristics of the sample: socio-demographics and attitudes}

The socio-demographic and attitudinal attributes of the interviewed consumers are shown in Table 2. According to the quota restrictions settled up in the recruitment, the distribution of gender and age are similar among the three countries. Regarding the other socio-demographics attributes only employment and income were found to be statistical significant differences across the countries investigated. Specifically, in Norway and Turkey similar patterns were found with a bit more public-sector employees for Norway and retired people for Turkey, while for Romania half of the sample is represented by private-sector workers with fewer students. Education level is very high (i.e. more than $3 / 4$ consumers have done university studies) and it is similar across the three countries, with a bit larger number of Norwegian consumers that have medium school level (11-14 years) compared to Romania and Turkey. In terms of income level compared to the respective national mean incomes, the Norwegian and Romanian consumers tend to have better personal economy than the Turkish consumers.

Further, the consumers investigated generally shows high health, natural and organic/ecological attitudes. Turkish and Romanian consumers have significantly larger health and natural product interest compared to Norwegian consumers, and in turn Romanian consumers have significantly larger organic and ecological attitudes compared to Turkish and Norwegian consumers. Romanian consumers also show a significantly higher food technology neophobia compared to Turkish and Norwegian consumers. 
Table 2 - Socio-demographic and attitudinal characteristics of the consumers in Norway, Turkey and Romania.

\subsection{Choice data analysis: estimation results}

The parameter estimates of the ML models for the main and interaction effects of the conjoint variables are presented in Table 3 for the three countries separately and for the pooled sample. For each ML model, the average parameter values and their significance levels are presented to the left while the corresponding standard deviations and significance levels are presented to the right. The latter values give an indication of the individual variability, also called preference heterogeneity, around the mean parameter value. The null hypothesis that all coefficients are zero is rejected by a Wald test ( $\mathrm{p}$-value <0.0005) for all the models, which implies that the attributes investigated in this research were considered relevant by the respondents.

Table 3 - Estimated parameters for ML models with conjoint variables' main effects and interactions for Norway, Romania and Turkey and the pooled sample.

\subsection{Main effects}

On average for the pooled sample, consumers prefer organic dried strawberries produced with conventional air-drying technology that have national origin, with natural nutrient content and at low price. In terms of magnitudes, technology is the most important factor followed by origin, nutrients and price. Specifically, we can notice that different national patterns arise for technology and origin, while for price the magnitudes are similar across countries. MW drying technology is more strongly rejected in Turkey followed by Romania and Norway. National origin is more strongly preferred in Norway, followed by Romania and Turkey. Turkish consumers reject high prices more strongly than Norwegian and Romanian consumers. Interestingly, the nutrient content 
factor is not significant in any country, but is significant at the overall level (pooled sample). The opt-out option has negative sign at pooled sample and individual country level meaning that on average consumers prefer one of the alternative products over the opt-out option. The standard deviations for all main effects are strong and significant both at overall level and for each country (with the exception of nutrients for Turkey), indicating the presence of a large preference heterogeneity across individuals.

\subsection{Interaction effects}

The model for the pooled sample does not present any significant interaction effect among conjoint variables, but several interactions are significant in the national models (Figure 2).

\section{Figure 2 - Significant interactions between conjoint factors at country levels.}

The interaction between Technology and Origin is significant for Norway and Turkey with opposite signs: in Norway, microwaved products are chosen significantly more often if they are of national origin compared to European origin, while choice of air-dried products, which are globally preferred, does not really depend on origin. In Turkey, air-dried products are chosen significantly more often if they are of national origin compared to European origin, while acceptance of microwaved products, which are globally rejected, does not really depend on origin. Further, the interaction effect Technology*Nutrients is significant in Romania, where MW drying is more strongly rejected in the case of basic nutrient content; in the case of more nutrients, technology doesn't really matter in this country. Last, the effect Nutrients* Origin is significant for Turkey, where national origin has a stronger positive effect on the choice of products with more natural nutrients than on the choice of products with basic natural nutrient content. 


\subsection{Preference heterogeneity}

\subsubsection{Drivers of individual choice differences in each country}

In order to investigate individual choice differences, four PCA models, respectively for Norway, Romania, Turkey and pooled sample were run on individual parameter estimates from the ML model above (i.e. model including only main effects and interactions of the conjoint factors). In the PCA models the coefficients are not standardized to preserve the original scale variations. Figure 3 shows the respective correlation loadings plot for each country and for the pooled sample. In Norway (Figure 3a), the first four principal components (PCs) indicate that the largest individual variations are linked to the No-buy option (on PC-1, explaining $65 \%$ of the variance), followed by Origin (PC-2, 18\%), Technology (PC-3, 15\%) and Nutrients content (on PC-4, 1\%). In Romania (Figure 3b), the largest individual variations are linked to Technology (PC-1, explaining 52\% of the variance), followed by No-buy option (PC-2, 31\%), Origin (PC-3,15\%) and Nutrients*Origin (PC4,2\%). In Turkey (Figure 3c), the largest individual variations are linked to Technology (on PC-1, explaining $41 \%$ of the variance), followed by Origin (PC-2, 32\%), No-buy option (PC-3, 27\%) and Nutrients content (PC-4, 1\%). In the pooled sample (Figure 3d), the largest individual variations are linked to No-buy option (on PC-1, explaining 44\% of the variance), followed by Technology (PC-2, 36\%), Origin (PC-3, 19\%) and Nutrients content $(\mathrm{PC}-4,1 \%)$. It is also interesting to note that factor Price nearly does not contribute to consumer variance at all in these models, indicating a strong consumer agreement on preference for low price levels.

Figure 3 - Drivers of preference heterogeneity. PCA correlation loadings plot (PC1 vs. PC2) on individual ML parameter estimates from choice data collected in Norway (a), Romania (b), Turkey (c) and pooled sample (d). Note: the attributes placed in the figure on the extremes of PC1 and PC2 have been superimposed to ease the interpretation. 


\subsubsection{Consumer attributes for air or microwave-drying technology preferences for the pooled sample}

Consumer attributes typical of air-drying or microwave-drying technology choices across the three countries were identified through a PLSR model relating the consumer attributes to the individual parameter estimates for factor Technology obtained from the mixed logit (ML) model. The final model explains $17 \%$ of the variation in Technology preferences with one PLS factor, indicating that the selected significant characteristics only partially explain consumers' technology choices. Out of 106 original variables, 27 show significant relationships to technology choices (Figure 4).

Figure 4 - Consumer profiles for technology preferences. PLSR loadings plots (PLSC1 vs. PLSC2) on consumer attributes and Mixed Logit parameter estimates for Technology from the pooled sample.

Consumers who most typically selected MW-dried products live in Norway, were in the age range 18-29 years old, agreed to the statements that "New food technologies are unlikely to have long term negative health effects" (AFTNS6) and "New products using new food technologies can help people have a balanced diet" (AFTNS8), purchase frozen conventional and organic berries (PurFroBer, PurFroBerOrg), purchase dairy products, drinks and jams based on berries (PurDaiBer, PurDrinkBer, PurBerJam), were often unemployed and often selected dried strawberries of national origin in the choice task.

Consumers who most typically selected air-dried products were Turkish in the age range 54-65 years old, presented high scores on the health interest (AGHI), natural interest (ANPI), organic and ecological attitudes (AFRLI) and food technology neophobia scales (FTNS), purchase dry and fresh berries in organic shops (DriBerOrSh, FreBerOrSh), stated that when purchasing dried fruits or berries it is important to them that the products are free from genetically modified organisms (NoGMOs), health-harming substances (NoHarmSub) and additives (NoAdditives, LeastAdditives) 
and pay attention to shelf life as a purchase criterion (ShelfLife), were often retired and often selected dried strawberries of high prices in the choice task. Note that attributes such as Romanian, gender or income do not appear in Figure 4 as these were neither significantly associated to microwave nor to air-drying technology preferences.

\subsubsection{Consumer attributes for air or microwave-drying technology preferences within each country}

Consumer attributes typical of air-drying or microwave-drying technology choices within each of the three countries were identified through country-specific PLSR models according to the same approach as for the cross-national model above. The final one-factor models explain $9 \%, 13 \%$ and $18 \%$ of the variation in Technology preferences for Norway, Romania and Turkey, respectively. This indicates that the selected significant attributes only partially explain consumers' technology choices. Out of 106 original variables, 8,18 and 23 variables show significant relationships to technology choices in Norway, Romania and Turkey, respectively.

Figure 5 shows that Norwegian respondents who most systematically selected microwave-dried strawberries in the choice task differed from those who most systematically selected air-dried products in that they adhered to the pro-technology statements "New food technologies give people more control over their food choices" (AFTNS7) and "New products using new food technologies can help people have a balanced diet" (AFTNS8) as well as rejected higher price levels in the choice task. On the contrary, air-dried organic strawberry choosers scored high on natural interest (ANPI) and organic attitudes (AFRLI) scales. They also stated that it is important to them that berry products are free from genetically modified organisms (NoGMOs), additives (LeastAdditives) and environment-friendly (EnvironmentallySound), and showed better acceptance for higher price levels in the choice task. No socio-demographic characteristics were significantly related to technology choices in this country. 
Figure 5 - Consumer attributes for technology preferences in the country-specific models. PLSR loadings plots for Norway.

Romanian respondents who most systematically selected microwave-dried strawberries in the choice task differed from those who most systematically selected air-dried products in that they purchase dried organic berries (PurDriOrgBer), berry drinks and jams (PurDrinkBer, PurBerJam), and frozen berries in online stores (PurFroBer, FroBerOnl) (Figure 6). They were typically from larger households (Hous-18, Hous+18) and in the age-range 18-29 yr. On the contrary, air-dried strawberry choosers scored high on health (AGHI), natural interest (ANPI) and organic attitudes (AFRLI) scales. They also stated that it is important to them that berry products are free from genetically modified organisms (NoGMOs), additives (NoAdditives, LeastAdditives) and without health-harming substances (NoHarmSub), and pay attention to shelf life as a purchase criterion (ShelfLife). These respondents were in the age-range 54-65 years old or retired.

Figure 6 - Consumer attributes for technology preferences in the country-specific models. PLSR loadings plots for Romania.

Turkish respondents who most systematically selected microwave-dried strawberries in the choice task differed from those who most systematically selected air-dried products in that they purchase dried organic berries (PurDriOrgBer), berry drinks (PurDrinkBer) and conventional and organic frozen berries (PurFroBer, PurFroBerOrg) in particular in organic shops (FroBerOrSh) (Figure 7). They adhered to the pro-technology statements "New food technologies are unlikely to have long term negative health effects" (AFTNS6) and "The media usually provides a balanced and unbiased view of new food technologies" (AFTNS13), were typically males and in the age-range 18-29 years old. 


\section{Figure 7 - Consumer attributes for technology preferences in the country-specific models.}

\section{PLSR loadings plots for Turkey.}

On the contrary, air-dried strawberry choosers scored high on the natural interest (ANPI) and food technology neophobia (FTNS) scales, adhering in particular to the statement "Society should not depend heavily on technologies to solve its food problems" (AFTNS11). They also stated that it is important to them that berry products are free from genetically modified organisms (NoGMOs), additives (NoAdditives, LeastAdditives), health-harming substances (NoHarmSub), and environment-friendly (EnvironmentallySound). They pay attention to shelf life (ShelfLife), convenience (Convenience), visibility of the product in the packaging (VisibleProduct) and origin (Imp_Origin) as purchase criteria for dried-berry products. These respondents were typically consumers of dried berries for snacking purposes (ConBerSnack) and females (Figure 7).

\section{DISCUSSION}

This paper aimed to two main objectives. First, we aimed to investigate consumers' preferences for organic dried strawberries focusing on two drying processing technologies, such as the conventional thermal air-drying and the innovative non-thermal MW drying and compare them across the countries investigated such as Norway, Romania and Turkey. We found that on average consumers prefer organic dried strawberries produced with the air-drying technology with national origin, natural nutrient content and low price. One possible explanation of the rejection of MW technology is that organic consumers who are particular sensitive to sustainable issues (i.e. organic, natural and ecological attitudes) might perceive the technology "unnatural". These findings are corroborated by previous research which found that in general consumers prefer food products produced with conventional food technologies (Lusk et al, 2014) while more specifically Hemmerling, Asioli, \& Spiller (2016) found that in several European countries organic consumers have preferences for conventional and traditional processing technologies. However, in general non-thermal food 
processing technologies are relatively well accepted by consumers (Fischer, van Trïpe, Hofenk, Ronteltap, \& Tudoran 2012), but some differences between specific technologies exist. Sonne et al. (2012) found that while high pressure pasteurisation (HPP) is quite accepted by consumers because it is easy to explain and linked to natural and healthy aspects, other technologies such as pulsed electric field (PEF) have led to a more sceptical response from consumers. It is possible that the rejection of MW might be linked to the lack of perceived naturalness and familiarity especially for organic consumers who might be more sensitive towards new food technologies. Concerning origin, several authors found that organic consumers have preferences for food products of national origin (Krystallis \& Chryssochoidis, 2009; Newman, Turri, Howlett, \& Stokes, 2014; Peterson, Bernard, Fox, \& Peterson, 2013). Gürhan-Canli \& Maheswaran (2000) found that collectivist cultures ${ }^{1}$ prefer national origin products over foreign products. Regarding the nutrient content, even if naturalness is perceived to be an important factor that drives consumer acceptance of new food technologies (Siegrist, 2008b), consumers prefer the natural nutrient content.

At national level we found interesting differences: Norwegian consumers show higher preferences for organic dried strawberries produced using MW technology than Romanian and Turkish consumers. A possible explanation is that in our sample, Norwegian consumers in general show a slightly lower food technology neophobia compared to Romanian and Turkish consumers. Another possible explanation of this behaviour is offered by Parrott, Wilson, \& Murdoch (2002) who claimed that two main food cultures exist that divide northern and southern European countries: while northern European countries give great emphasis on functionality-driven commodities and economic efficiency in food production, southern European countries provide more value to local, traditional, and artisanal production. Interestingly, origin plays a role in the acceptance of MW: Norwegians accept MW products if they are of national origin, while Turks accept air-dried products if they are of national origin. In this study, nutrients content was an important driver of

\footnotetext{
${ }^{1}$ A collectivistic culture (e.g. Japan) is a culture when people feel they belong to larger in-groups or collectives which care for them in exchange for loyalty - and vice versa while the on the contrary an individualistic culture (e.g. US) is a culture where people are concerned with themselves and close family members only (Hofstede \& Bond, 1984).
} 
choice at global level, but not in individual countries. It is possible that dried berries are considered as a healthy and nutritious food to start with, such that nutrients information is not a search attribute for this type of products. We also found significant consumer heterogeneities both at global level and within each country, which indicates that different consumer segments could be characterized. Drying technology was the main driver of individual differences in Romania and Turkey, but not in Norway where MW-drying was widely accepted in combination with national production. This indicates that in Norway, organic production and national production may be cues of safety, reducing consumers' reluctance to new food technologies. It also illustrates that Norwegian consumers prefer national product origin and trust the Norwegian food industry (Asioli \& Alfnes, 2016).

Second, we investigated individual technology preferences and characterized consumer profiles in terms of attitudes, habits and socio-demographics across the different countries. We found that at global level consumer attributes only partially explain the attitude towards technology. Respondents who showed a least rejection for MW dried organic strawberries are young, live in Norway and have positive attitudes towards new food technologies. On the other hand, consumers who preferred air-drying products are typically older, live in Turkey and have pro-attitudes for organic, natural and ecological behaviour. Results show that younger consumers were more positive towards MW-dried products than older consumers. This finding is corroborated by Tuorila, Lähteenmäki, Pohjalainen, \& Lotti (2001). Norwegians who prefer dried organic strawberries produced with MW drying show positive attitudes for new food technologies, while consumers who prefer air drying products show interest for organic and natural food products, and show a willingness to pay (WTP) higher prices as well as prefer to buy berries that are GMO-free, do not contain additives and are environmentalfriendly produced. A similar path has been identified for Romanian consumers as well as for Turkish consumers.

\section{CONCLUSION}


The results of this research show that producers aiming to produce and sell organic dried strawberries using MW drying should carefully identify specific consumers segments to target their marketing strategies. For example, it appears that an initial focus towards younger consumers as early adopters, in particular in Norway, would help the launch of MW products before extending to other consumer segments. To increase consumer acceptance of MW berries products, it is very important to inform consumers about the process and benefits of such technology and its characteristics (i.e. non-thermal and organic) since being a credence attribute it cannot be directly experienced by consumers. The benefits and the process of MW should be communicated by the industry and/or by independent scientist or consumer organizations to increase consumer trust (Siegrist, 2008b). Special attention should be brought on how to frame the communication since organic consumers are more sensitive to health, environmental and ecological issues than nonorganic consumers. For policy makers it is important to define and regulate more clearly the microwave drying as organic technology as well as regulate the labeling to ensure that consumers are not mislead and correctly informed about the new technology.

Future research avenues could be addressed in several directions. First, investigations of different product communication framings may allow to verify which ones are more accepted by consumers and best reinforce consumers' trust in non-thermal processing technologies of organic products. Second, the investigation of additional non-thermal processing technologies and labeling strategies would enrich the knowledge about organic consumers' acceptance towards those technologies. Last, the replication of this study in other countries by using organic products of different levels of processing and in non-hypothetical buying scenarios, would be useful to further investigate consumers' perception for organic processed products.

Finally, the results from this study show that consumers who have stronger ecological and environmental attitudes are more reluctant to adopt MW drying even if it is an organic processing 
technology. As expressed by Cavaliere \& Ventura (2018), consumers with high sustainable concerns fail to recognize in science and technology a possible contribution towards a more sustainable world. 


\section{Acknowledgments}

Financial support for this project is provided by funding bodies within the FP7 ERA-Net CORE

Organic Plus, and with cofunds from the European Commission. Author C. Rocha acknowledges Industry Doctoral grant No. SFRH/BDE/100483/2014, funded by FCT, Portuguese Foundation for Science and Technology (FCT). Thanks also to the European Commission through the Marie Curie Actions Intra European Fellowship (IEF), call FP/-PEOPLE-I2012-IEF - project title “Innovative Methodologies for New Food Product Development: combining Sensory Science and Experimental Economics - NEFOMET” for the support. 


\section{REFERENCES}

Aday, M. S., \& Caner, C. (2014). Individual and combined effects of ultrasound, ozone and chlorine dioxide on strawberry storage life. LWT - Food Science and Technology, 57(1), 344-351.

Aguilera, J. M., Chiralt, A., \& Fito, P. (2003). Food dehydration and product structure. Trends in Food Science \& Technology, 14(10), 432-437.

Almli, V., \& Naes, T. (2018). Conjoint Analysis in Sensory and Consumer Science: Principles, Applications, and Future Perspectives. In Methods in Consumer Research (pp. 485-529).

Almli, V., Øvrum, A., Hersleth, M., Almøy, T., \& Næs, T. (2015). Investigating individual preferences in rating and ranking conjoint experiments. A case study on semi-hard cheese. Food Quality and Preference, 39, 28-39.

Aschemann, J., Hamm, U., Naspetti, S., \& Zanoli, R. (2007). The organic market. In W. Lockeretz (Ed.), Organic farming - an international history. (pp. 123-151). Oxfordshire/UK and Cambridge/MA/US A: CAB International.

Asioli, D., \& Alfnes, F. (2016). Guest editorial. British Food Journal, 118(10).

Asioli, D., Almli, V., \& Næs, T. (2016). Comparison of two different strategies for investigating individual differences among consumers in choice experiments. A case study based on preferences for iced coffee in Norway. Food Quality and Preference, 54, 79-89.

Asioli, D., Aschemann-Witzel, J., Caputo, V., Vecchio, R., Annunziata, A., Næs, T., \& Varela, P. (2017). Making sense of the "clean label" trends: A review of consumer food choice behavior and discussion of industry implications. Food Research International, 99(1), 58-71.

Asioli, D., Næs, T., Øvrum, A., \& Almli, V. L. (2016). Comparison of rating-based and choicebased conjoint analysis models. A case study based on preferences for iced coffee in Norway. Food 
Quality and Preference, 48, 174-184.

Awsi, J., Monika, S., SA, S., \& Tsering, N. (2017). Non-thermal processing in food applications: A review. International Journal of Food Science and Nutrition, 2(6), 171-180.

Basu, A., Nguyen, A., Betts, N. M., \& Lyons, T. J. (2014). Strawberry As a Functional Food: An Evidence-Based Review. Critical Reviews in Food Science and Nutrition, 54(6), 790-806.

Bech, M., \& Gyrd-Hansen, D. (2005). Effects coding in discrete choice experiments. Health Economics, 14(10), 1079-1083.

Bhat, R., Geppert, J., Funken, E., \& Stamminger, R. (2015). Consumers Perceptions and Preference for Strawberries_-A Case Study from Germany. International Journal of Fruit Science, 15(4), 405424.

Bourn, D., \& Prescott, J. (2002). A Comparison of the Nutritional Value, Sensory Qualities, and Food Safety of Organically and Conventionally Produced Foods. Critical Reviews in Food Science and Nutrition, 42(1), 1-34.

Briz, T., Sijtsema, S. J., Jasiulewicz, A., Kyriakidi, A., Guàrdia, M. D., Berg, I. van den, \& Lans, I. A. van der. (2008). Barriers to Fruit Consumption: Driving Forces behind Consumer Behaviour. Scripta Horticulturae, 8, 7-18.

Bruns $\varnothing$, K., \& Grunert, K. G. (1995). Development and testing of a cross-culturally valid instrument: Food-related lifestyle. Advances in Consumer Research, 22, 475-480.

Canavari, M., Nocella, G., \& Scarpa, R. (2005). Stated willingness-to-pay for organic fruit and pesticide ban: an evaluation using both web-based and face-to-face interviewing. Journal of Food Products Marketing, 11(3), 107-134.

Cavaliere, A., \& Ventura, V. (2018). Mismatch between food sustainability and consumer 
acceptance toward innovation technologies among Millennial students: The case of Shelf Life Extension. Journal of Cleaner Production, 175, 641-650.

Chandrasekaran, S., Ramanathan, S., \& Basak, T. (2013). Microwave food processing-A review. Food Research International, 52(1), 243-261.

Chizoba Ekezie, F.-G., Sun, D.-W., Han, Z., \& Cheng, J.-H. (2017). Microwave-assisted food processing technologies for enhancing product quality and process efficiency: A review of recent developments. Trends in Food Science \& Technology, 67, 58-69.

Choice Metrics. (2012). Ngene 1.1.1. User Manual \& Reference Guide. ChoiceMetrics. Australia.

Cox, D. N., \& Evans, G. (2008). Construction and validation of a psychometric scale to measure consumers' fears of novel food technologies: The food technology neophobia scale. Food Quality and Preference, 19(8), 704-710.

Dehghannya, J., Hosseinlar, S.-H., \& Heshmati, M. K. (2018). Multi-stage continuous and intermittent microwave drying of quince fruit coupled with osmotic dehydration and low temperature hot air drying. Innovative Food Science \& Emerging Technologies, 45, 132-151.

Dev, S. R. S., \& Raghavan, V. G. S. (2012). Advancements in Drying Techniques for Food, Fiber, and Fuel. Drying Technology, 30(11-12), 1147-1159.

Endrizzi, I., Menichelli, E., Johansen, S. B., Olsen, N. V., \& Næs, T. (2011). Handling of individual differences in rating-based conjoint analysis. Food Quality and Preference, 22(3), 241-254.

European Commission. (2007). Council Regulation (EC) No 834/2007 of 28 June 2007 on organic production and labelling of organic products and repealing Regulation (EEC) No 2092/91.

European Commission. (2018). REGULATION (EU) 2018/848 OF THE EUROPEAN

PARLIAMENT AND OF THE COUNCIL of 30 May 2018 on organic production and labelling of 
organic products and repealing Council Regulation (EC) No 834/2007.

Evans, G., Kermarrec, C., Sable, T., \& Cox, D. N. (2010). Reliability and predictive validity of the Food Technology Neophobia Scale. Appetite, 54(2), 390-393.

Farruggia, D., Crescimanno, M., Galati, A., \& Tinervia, S. (2016). The Quality Perception of Fresh Berries: An Empirical Survey in the German Market. Agriculture and Agricultural Science Procedia, 8, 566-575.

Fellows, P. J. (2017a). 7 - Minimal processing methods. In P. J. B. T.-F. P. T. (Fourth E. Fellows (Ed.), Woodhead Publishing Series in Food Science, Technology and Nutrition (pp. 431-512). Woodhead Publishing.

Fellows, P. J. (2017b). 7 - Minimal processing methods. In P. J. B. T.-F. P. T. (Fourth E. Fellows (Ed.), Woodhead Publishing Series in Food Science, Technology and Nutrition (pp. 431-512). Woodhead Publishing.

FIBL. (2017). The World of Organic Agriculture. (H. Willer \& J. Lernoud, Eds.). Frick, Switzerland.

Fischer. A, van Trijpe, H., Hofenk, D., Ronteltap, A., \& Tudoran, A. (2012). Collation of Scientific Evidence on Consumer Acceptance of New Food Technologies: Three roads to consumer choice. D2.2: Collation of Scientific Evidence on Consumer Acceptance of New Food Technologies: 2012.

Giordano, S., Clodoveo, M. L., Gennaro, B. De, \& Corbo, F. (2018). Factors determining neophobia and neophilia with regard to new technologies applied to the food sector: A systematic review. International Journal of Gastronomy and Food Science, 11, 1-19.

Grunert, K. G. (2013). Trends in food choice and nutrition. In M. Klopčič, A. Kuipers, \& J.-F. Hocquette (Eds.), Consumer attitudes to food quality products: Emphasis on Southern Europe (pp. 
23-30). Wageningen: Wageningen Academic Publishers.

Grunert, K. G., Bredahl, L., \& Scholderer, J. (2003). Four questions on European consumers' attitudes toward the use of genetic modification in food production. Innovative Food Science \& Emerging Technologies, 4(4), 435-445.

Guo, Q., Sun, D.-W., Cheng, J.-H., \& Han, Z. (2017). Microwave processing techniques and their recent applications in the food industry. Trends in Food Science \& Technology, 67, 236-247.

Gürhan-Canli, Z., \& Maheswaran, D. (2000). Determinants of Country-of-Origin Evaluations. Journal of Consumer Research, 27(1), 96-108.

Häkkinen, S. H., \& Törrönen, A. R. (2000). Content of flavonols and selected phenolic acids in strawberries and Vaccinium species: influence of cultivar, cultivation site and technique. Food Research International, 33(6), 517-524.

Harker, F. R., Gunson, F. A., \& Jaeger, S. R. (2003). The case for fruit quality : an interpretive review of consumer attitudes, and preferences for apples. Postharvest Biology and Technology, 28(3), 333-347.

Hemmerling, S., Asioli, D., \& Spiller, A. (2016). Core Organic Taste: Preferences for NaturalnessRelated Sensory Attributes of Organic Food Among European Consumers. Journal of Food Products Marketing, 22(7), 824-850.

Hensher, D., Rose, J. M., \& Green, W. (2015). Applied Choice Analysis (2nd ed.). Cambridge: Cambride University Press.

Hinson, R. A., \& Bruchhaus, M. N. (2008). Consumer Preferences for Locally Produced Strawberries. Journal of Food Distribution Research, 39(3), 56-66.

Hofstede, G., \& Bond, M. H. (1984). Hofstede's Culture Dimensions: An Independent Validation 
Using Rokeach's Value Survey. Journal of Cross-Cultural Psychology, 15(4), 417-433.

Hole, A. R. (2007). Fitting mixed logit models by using maximum simulated likelihood. The Stata Journal, 7(3), 188-401.

IFOAM. (2015). Into the future. Consolidated Annual Report. Retrieved from http $/ /$ www.ifoam.bio/sites/default/files/annual_report_2015_0.pdf

Invenire Market Intelligence. (2008). Berries in the world.

Jaeger, S. R., \& Rose, J. M. (2008). Stated choice experimentation, contextual influences and food choice: A case study. Food Quality and Preference, 19(6), 539-564.

Jesionkowska, K., Sijtsema, S. J., Konopacka, D., \& Symoneaux, R. (2009). Dried fruit and its functional properties from a consumer's point of view. The Journal of Horticultural Science and Biotechnology, 84(6), 85-88.

Jia, N., Kong, B., Liu, Q., Diao, X., \& Xia, X. (2012). Antioxidant activity of black currant (Ribes nigrum L.) extract and its inhibitory effect on lipid and protein oxidation of pork patties during chilled storage. Meat Science, 91(4), 533-539.

Kahl, J., Baars, T., Bügel, S., Busscher, N., Huber, M., Kusche, D., ... Załę cka, A. (2012). Organic food quality: a framework for concept, definition and evaluation from the European perspective. Journal of the Science of Food and Agriculture, 92(14), 2760-2765.

Kearney, J. (2010). Food consumption trends and drivers. Philosophical Transactions of the Royal Society B: Biological Sciences, 365(1554), 2793-2807.

Kretzschmar, U., \& Schmid, O. (2011). Quality and safety aspects of organic and low-input food processing: Results of a Delphi survey from an expert consultation in 13 European countries. NJAS - Wageningen Journal of Life Sciences, 58(3-4), 111-116. 
Krystallis, A., \& Chryssochoid is, G. (2009). Does the Country of Origin (COO) of Food Products

Influence Consumer Evaluations? An Empirical Examination of Ham and Cheese. Journal of Food Products Marketing, 15(3), 283-303.

Lachat, C., Nago, E., Verstraeten, R., Roberfroid, D., Van Camp, J., \& Kolsteren, P. (2012). Eating out of home and its association with dietary intake: a systematic review of the evidence. Obesity Reviews : An Official Journal of the International Association for the Study of Obesity, 13(4), $329-46$.

Lancaster, K. (1966). A new approach to consumer theory. Journal of Political Economy, 7, 132.

Li, Z. Y., Wang, R. F., \& Kudra, T. (2011). Uniformity Issue in Microwave Drying. Drying Technology, 29(6), 652-660.

Louviere, Hensher, \& Swait. (2000). Stated choice methods. Analysis and applications. Cambridge: Cambridge University Press.

Lusk, J. L., Roosen, J., \& Bieberstein, A. (2014). Consumer Acceptance of New Food Technologies: Causes and Roots of Controversies. Annual Review of Resource Economics, 6(1), $381-405$.

Lusk, J. L., \& Schroeder, T. C. (2004). Are Choice Experiments Incentive Compatible? A Test with Quality Differentiated Beef Steaks. American Journal of Agricultural Economics , 86(2), 467-482.

Martens, H., \& Martens, M. (2000). Modified Jack-knife estimation of parameter uncertainty in bilinear modelling by partial least squares regression (PLSR). Food Quality and Preference, 11(12), 5-16.

Meyers, K. J., Watkins, C. B., Pritts, M. P., \& Liu, R. H. (2003). Antioxidant and Antiproliferative Activities of Strawberries. Journal of Agricultural and Food Chemistry, 51(23), 6887-6892. 
Moses, J. A., Norton, T., Alagusundaram, K., \& Tiwari, B. K. (2014). Novel Drying Techniques for the Food Industry. Food Engineering Reviews, 6(3), 43-55.

Moses, J., Paramasivan, K., R, S. V, \& Kumar, T. B. (2013). Effect of Microwave Treatment on Drying Characteristics and Quality Parameters of Thin Layer Drying of Coconut. Asian Journal Food Agriculture Industry, 6(2), 72-85.

Newman, C. L., Turri, A. M., Howlett, E., \& Stokes, A. (2014). Twenty Years of Country-of-Origin Food Labeling Research: A Review of the Literature and Implications for Food Marketing Systems. Journal of Macromarketing, 34(4), 505-519.

Orsat, V., Changrue, V., \& Raghavan, V. G. S. (2006). Microwave drying of fruits and vegetables. Stewart Postharvest Review, 2(6), 1-7.

Ortúzar, J. de D. (2010). Estimating individual preferences with flexible discrete-choice-models. Food Quality and Preference, 21(3), 262-269.

Panico, T., Del Giudice, T., Cicia, G., \& Cembalo, L. (2011). Consumption of organic strawberries in Italy: demand analysis. New Medit, 3, 11-16.

Parrott, N., Wilson, N., \& Murdoch, J. (2002). Spatializing Quality: Regional Protection and the Alternative Geography of Food. European Urban and Regional Studies, 9(3), 241-261.

Peterson, H. H., Bernard, J. C., Fox, J. A. (Sean), \& Peterson, J. M. (2013). Japanese Consumers' Valuation of Rice and Pork from Domestic, U.S., and Other Origins. Journal of Agricultural and Resource Economics, 38(1), 93-106.

Raghavan, G. S. V, Rennie, T. J., Sunjka, P. S., Orsat, V., Phaphuangwittayakul, W., \& Terdtoon, P. (2005). Overview of new techniques for drying biological materials with emphasis on energy aspects. Brazilian Journal of Chemical Engineering, 22, 195-201. 
Roininen, K., Lähteenmäki, L., \& Tuorila, H. (1999). Quantification of Consumer Attitudes to Health and Hedonic Characteristics of Foods. Appetite, 33(1), 71-88.

Salgado-Beltrán, L., Beltrán-Morales, F. L., Velarde-Mendivil, T. A., \& Robles-Baldene gro, E. M. (2018). Attitudes and Sensory Perceptions of Food Consumers towards Technological Innovation in Mexico: A Case-Study on Rice-Based Dessert. Sustainability, 10, 175.

Scarpa, R., \& Del Giudice, T. (2004). Market segmentation via mixed logit: extra-virgin olive oil in urban Italy. Journal of Agricultural \& Food Industrial Organization, 2(1, article 7).

Schnettler, B., Miranda, H., Sepúlveda, J., Denegri, M., Mora, M., \& Lobos, G. (2011). Preferences for Berries Among Consumers in Southern Chile: Blueberries Are Produced but Are They Consumed? Journal of Food Science, 76(7), S458-S464.

Siegrist, M. (2008a). Factors influencing public acceptance of innovative food technologies and products. Trends in Food Science \& Technology, 19(11), 603-608.

Siegrist, M. (2008b). Factors influencing public acceptance of innovative food technologies and products. Trends in Food Science \& Technology, 19(11), 603-608.

Sonne, A., Grunert, K. G., Olsen, N. V., Granli, B., Szabó, E., \& Banati, D. (2012). Consumers' perceptions of HPP and PEF food products. British Food Journal, 114(1), 85-107.

Szajdek, A., \& Borowska, E. J. (2008). Bioactive Compounds and Health-Promoting Properties of Berry Fruits: A Review. Plant Foods for Human Nutrition, 63(4), 147-156.

Tanase, E. E., V.I., P., M.E., P., Geicu-Cristea M., P. P., M., D., \& A.C., M. (2016). Identification of the most relevant quality parameters for berries - A review. Scientific Bulletin. Series F. Biotechnologies, XX, 222-236.

Thøgersen, J., Pedersen, S., Paternoga, M., Schwendel, E., \& Aschemann-Witzel, J. (2017). How 
important is country-of-origin for organic food consumers? A review of the literature and suggestions for future research. British Food Journal, 119(3), 542-557.

Thurstone, L. L. (1927). A law of comparative judgment. Psychological Review, 34, 273-286.

Train. (2009). Discrete choice methods with simulation. (C. U. Press, Ed.), New York (Vol. 47). Cambridge University Press.

Tuorila, H., Lähteenmäki, L., Pohjalainen, L., \& Lotti, L. (2001). Food neophobia among the Finns and related responses to familiar and unfamiliar foods. Food Quality and Preference, 12(1), 29-37.

Vadivambal, R., \& Jayas, D. S. (2007). Changes in quality of microwave-treated agricultural products - a review. Biosystems Engineering, 98(1), 1-16.

Van Kleef, E., Van Trijp, H. C. M., \& Luning, P. (2005). Consumer research in the early stages of new product development: a critical review of methods and techniques. Food Quality and Preference, 16(3), 181-201.

Van Loo, E., Caputo, V., Nayga, R., \& Verbeke, W. (2014). Consumers' valuation of sustainability labels on meat. Food Policy, 49, Part 1, 137-150.

Van Wezemael, L., Caputo, V., Nayga, R. M., Chryssochoidis, G., \& Verbeke, W. (2014). European consumer preferences for beef with nutrition and health claims: A multi-country investigation using discrete choice experiments. Food Policy, 44, 167-176.

Wang, S. Y., \& Gao, H. (2013). Effect of chitosan-based edible coating on antioxidants, antioxidant enzyme system, and postharvest fruit quality of strawberries (Fragaria $\mathrm{x}$ aranassa Duch.). LWT Food Science and Technology, 52(2), 71-79.

Wang, Z., Narciso, J., Biotteau, A., Plotto, A., Baldwin, E., \& Bai, J. (2014). Improving Storability of Fresh Strawberries with Controlled Release Chlorine Dioxide in Perforated Clamshell Packaging. 
Food and Bioprocess Technology, 7(12), 3516-3524.

Weis, T. (2007). The Global Food Economy: The Battle for the Future of Farming. Canada:

Fernowood Publishing.

WHO. (2003). Diet, nutrition and the prevention of choronic disease. Geneve.

Wojdyło, A., Figiel, A., Lech, K., Nowicka, P., \& Oszmiański, J. (2014). Effect of Convective and Vacuum-Microwave Drying on the Bioactive Compounds, Color, and Antioxidant Capacity of Sour Cherries. Food and Bioprocess Technology, 7(3), 829-841.

Wojdyło, A., Figiel, A., \& Oszmiański, J. (2009). Effect of Drying Methods with the Application of Vacuum Microwaves on the Bioactive Compounds, Color, and Antioxidant Activity of Strawberry Fruits. Journal of Agricultural and Food Chemistry, 57(4), 1337-1343.

Wray, D., \& Ramaswamy, H. S. (2015). Novel Concepts in Microwave Drying of Foods. Drying Technology, 33(7), 769-783.

Wu, R., Frei, B., Kennedy, J. A., \& Zhao, Y. (2010). Effects of refrigerated storage and processing technologies on the bioactive compounds and antioxidant capacities of 'Marion' and 'Evergreen' blackberries. LWT - Food Science and Technology, 43(8), 1253-1264.

Zarein, M., Samadi, S. H., \& Ghobadian, B. (2015). Investigation of microwave dryer effect on energy efficiency during drying of apple slices. Journal of the Saudi Society of Agricultural Sciences, 14(1), 41-47.

Zhang, M., Tang, J., Mujumdar, A. S., \& Wang, S. (2006). Trends in microwave-related drying of fruits and vegetables. Trends in Food Science \& Technology, 17(10), 524-534.

Zhou, G., Hu, W., \& Huang, W. (2016). Are Consumers Willing to Pay More for Sustainable Products? A Study of Eco-Labeled Tuna Steak. Sustainability, 8(5), 494. 
Zielinska, M., \& Markowski, M. (2016). The influence of microwave-assisted drying techniques on the rehydration behavior of blueberries (Vaccinium corymbosum L.). Food Chemistry, 196, 11881196.

Zielinska, M., \& Michalska, A. (2016). Microwave-assisted drying of blueberry (Vaccinium corymbosum L.) fruits: Drying kinetics, polyphenols, anthocyanins, antioxidant capacity, colour and texture. Food Chemistry, 212, 671-680.

Zielinska, M., Sadowski, P., \& Błaszczak, W. (2015). Freezing/thawing and microwave-assisted drying of blueberries (Vaccinium corymbosum L.). LWT - Food Science and Technology, 62(1), $555-563$. 
Table 1 - Attribute levels used in the study

\begin{tabular}{|c|c|}
\hline ATTRIBUTE & CODE AND LEVEL \\
\hline Origin & $\begin{array}{l}-1 \text { Europe } \\
+1 \text { Own country (Norway, Romania or Turkey) }\end{array}$ \\
\hline Technology & $\begin{array}{l}\text { - } 1 \text { Air drying } \\
+1 \text { Microwave drying }\end{array}$ \\
\hline Nutrition content & $\begin{array}{l}\text { - } 1 \text { Natural nutrients (Antioxidants, Vitamin C and Fibres) } \\
+1 \text { More natural nutrients (Antioxidants, Vitamin C and Fibres) }\end{array}$ \\
\hline Price & $\begin{array}{l}-10 \% \text { (63 NOK in Norway; 20 Lei in Romania; 3.4 TL in Turkey) } \\
0 \quad(70 \text { NOK in Norway; 22 Lei in Romania; 3.8 TL in Turkey) } \\
+10 \% \text { (77 NOK in Norway; } 24 \text { Lei in Romania; } 4.2 \text { TL in Turkey) }\end{array}$ \\
\hline
\end{tabular}


Table 2 - Socio-demographic and attitudinal characteristics of the consumers in Norway,

Turkey and Romania.

\begin{tabular}{|c|c|c|c|c|}
\hline ATTRIBUTES & $\begin{array}{c}\text { NORWAY } \\
(\mathrm{n}=\mathbf{2 0 4})\end{array}$ & $\begin{array}{c}\text { ROMANIA } \\
(n=206)\end{array}$ & $\begin{array}{c}\text { TURKEY } \\
(n=204)\end{array}$ & $\begin{array}{c}\text { POOLED } \\
(n=614)\end{array}$ \\
\hline \multicolumn{5}{|l|}{ SOCIO-DEMOGRAPHICS : Number (\%) } \\
\hline $\begin{array}{l}\text { Gender } \\
\text { Male } \\
\text { Female }\end{array}$ & $\begin{array}{l}102(50.0 \%) \\
102(50.0 \%)\end{array}$ & $\begin{array}{l}104(50.5 \%) \\
102(49.5 \%)\end{array}$ & $\begin{array}{l}102(50 \%) \\
102(50 \%)\end{array}$ & $\begin{array}{l}308(50.2 \%) \\
306(49.8 \%)\end{array}$ \\
\hline $\begin{array}{l}\text { Age } \\
18-29 y r \\
30-41 y r \\
42-53 y r \\
54-65 y r\end{array}$ & $\begin{array}{l}53(26.0 \%) \\
53(26.0 \%) \\
50(24.5 \%) \\
48(23.5 \%)\end{array}$ & $\begin{array}{l}53(25.7 \%) \\
53(25.7 \%) \\
47(22.8 \%) \\
53(25.7 \%)\end{array}$ & $\begin{array}{l}53(26 \%) \\
53(26 \%) \\
45(22 \%) \\
53(26 \%)\end{array}$ & $\begin{array}{l}159(25.9 \%) \\
159(25.9 \%) \\
142(23.1 \%) \\
154(25.1 \%)\end{array}$ \\
\hline $\begin{array}{l}\text { Employment } \\
\text { Student } \\
\text { Independent worker } \\
\text { Private-sector worker } \\
\text { Public-sector worker } \\
\text { Retired } \\
\text { Unemployed } \\
\text { Other }\end{array}$ & $\begin{array}{l}28(13.7 \%) \\
13(6.4 \%) \\
65(31.9 \%) \\
60(29.4 \%) \\
15(7.4 \%) \\
23(11.3 \%) \\
0(0.00 \%)\end{array}$ & $\begin{array}{c}3(1.5 \%) \\
11(5.3 \%) \\
101(49.0 \%) \\
51(24.8 \%) \\
25(12.1 \%) \\
7(3.4 \%) \\
8(3.9 \%)\end{array}$ & $\begin{array}{l}20(9.8 \%) \\
15(7.4 \%) \\
60(29.9 \%) \\
42(20.6 \%) \\
40(19.6 \%) \\
22(10.8 \%) \\
5(2.3 \%)\end{array}$ & $\begin{array}{c}51(8.3 \%) \\
39(6.4 \%) \\
226(36.8 \%) \\
153(24.9 \%) \\
80(13.4 \%) \\
52(8.5 \%) \\
13(2.1 \%)\end{array}$ \\
\hline $\begin{array}{l}\text { Education } \\
\text { Elementary school (6-10 yr) } \\
\text { Medium school }(11-14 \mathrm{yr}) \\
\text { High school }(15-18 \mathrm{yr}) \\
\text { University }(+18 \mathrm{yr})\end{array}$ & $\begin{array}{c}0(0.00 \%) \\
10(4.90 \%) \\
47(23.04 \%) \\
174(72.06 \%)\end{array}$ & $\begin{array}{c}1(0.49 \%) \\
1(0.49 \%) \\
37(17.96 \%) \\
167(81.07 \%)\end{array}$ & $\begin{array}{c}0(0.00 \%) \\
0(0.00 \%) \\
32(15.69 \%) \\
172(84.31 \%)\end{array}$ & $\begin{array}{c}1(0.16 \%) \\
11(1.79 \%) \\
116(18.89 \%) \\
486(79.15 \%)\end{array}$ \\
\hline $\begin{array}{l}\text { Monthly household income after tax } \\
\text { Less than } 0.5 * \text { average } \\
\text { Between } 0.5 * \text { average and average } \\
\text { Between average and } 1.5 * \text { average } \\
\text { More than } 1.5 * \text { average } \\
\text { I don't know/I don't want to disclose }\end{array}$ & $\begin{array}{l}20(9.8 \%) \\
67(32.8 \%) \\
60(29.4 \%) \\
30(14.7 \%) \\
27(13.2 \%) \\
\end{array}$ & $\begin{array}{c}30(14.6 \%) \\
79(38.3 \%) \\
63(30.6 \%) \\
26(12.6 \%) \\
8(3.9 \%) \\
\end{array}$ & $\begin{array}{l}69(33.8 \%) \\
95(46.6 \%) \\
21(10.3 \%) \\
7(3.4 \%) \\
12(5.9 \%) \\
\end{array}$ & $\begin{array}{c}119(19.4 \%) \\
241(39.3 \%) \\
144(23.5 \%) \\
63(10.3 \%) \\
47(7.7 \%)\end{array}$ \\
\hline \multicolumn{5}{|c|}{ ATTITUDES $^{2}$ : Mean, $(S D)$, Cronbach's alpha } \\
\hline Health attitude (HTAQ) & $\begin{array}{c}4.64^{\mathrm{a}} \\
(0.79) \\
0.74\end{array}$ & $\begin{array}{c}4.94^{\mathrm{b}} \\
(0.93) \\
0.77 \\
\end{array}$ & $\begin{array}{c}5.07^{b} \\
(0.93) \\
0.75 \\
\end{array}$ & $\begin{array}{c}4.89 \\
(1.00) \\
0.75\end{array}$ \\
\hline Natural attitude (HTAQ) & $\begin{array}{l}4.44^{\mathrm{a}} \\
(1.16) \\
0.77\end{array}$ & $\begin{array}{c}5.26^{\mathrm{b}} \\
(0.96) \\
0.57\end{array}$ & $\begin{array}{l}5.31^{\mathrm{b}} \\
(1.03) \\
0.66\end{array}$ & $\begin{array}{c}5.00 \\
(1.12) \\
0.71\end{array}$ \\
\hline Organic and ecological attitudes (FRL) & $\begin{array}{c}4.15^{\mathrm{a}} \\
(1.40) \\
0.78 \\
\end{array}$ & $\begin{array}{c}5.64^{\mathrm{b}} \\
(1.11) \\
0.80\end{array}$ & $\begin{array}{c}5.35^{\mathrm{c}} \\
(1.25) \\
0.73 \\
\end{array}$ & $\begin{array}{c}5.05 \\
(1.42) \\
0.80\end{array}$ \\
\hline Food technology neophobia (FTNS) & $\begin{array}{c}4.18^{\mathrm{a}} \\
(0.91) \\
0.86 \\
\end{array}$ & $\begin{array}{c}4.60^{b} \\
(0.78) \\
0.78 \\
\end{array}$ & $\begin{array}{c}4.43^{\mathrm{c}} \\
(0.91) \\
0.79 \\
\end{array}$ & $\begin{array}{c}4.40 \\
(0.89) \\
0.79 \\
\end{array}$ \\
\hline
\end{tabular}

${ }^{1}$ In Norway: Less than 23000 NOK/23000-46999 NOK/47000-71000 NOK/More than 71000 NOK; In Romania: Less than 21000 RON/2100-4199,99 RON/4200-6300 RON/More than 6300 RON ; In Turkey: Less than 3750 TL/3750-7499 TL/7500-11250 TL/More than 11250 TL.

${ }^{2}$ Seven-point Likert scales ranging from $1=$ strongly disagree to $7=$ stronglyagree were used to measure consumer attitudes.

${ }^{a, b, c}$ Significant differences based on Chi-squared and Pearson Chi-squared tests. Same letter indicates that there is no statistical significant difference at $5 \%$ level. 
Table 3 - Estimated parameters for ML models with conjoint variables' main effects and interactions for Norway, Romania and Turkey and the pooled sample.

\begin{tabular}{|c|c|c|c|c|c|c|c|c|}
\hline \multirow[t]{2}{*}{ EFFECTS } & \multicolumn{2}{|c|}{$\begin{array}{c}\text { NORWAY } \\
(\mathrm{n}=\mathbf{2 0 4})\end{array}$} & \multicolumn{2}{|c|}{$\begin{array}{c}\text { ROMANIA } \\
(\mathrm{n}=206)\end{array}$} & \multicolumn{2}{|c|}{$\begin{array}{c}\text { TURKEY } \\
(n=204)\end{array}$} & \multicolumn{2}{|c|}{$\begin{array}{c}\text { POOLED S AMPLE } \\
(n=614)\end{array}$} \\
\hline & $\begin{array}{l}\text { ESTIMATE } \\
\text { (p) }\end{array}$ & $\begin{array}{l}S D \\
(p)\end{array}$ & $\begin{array}{c}\text { ES TIMATE } \\
(\mathbf{p})\end{array}$ & $\begin{array}{l}S D \\
(\mathbf{p})\end{array}$ & $\begin{array}{c}\text { ES TIMATE } \\
\text { (p) }\end{array}$ & $\begin{array}{l}S D \\
(\mathbf{p})\end{array}$ & $\begin{array}{l}\text { ESTIMATE } \\
\text { (p) }\end{array}$ & $\begin{array}{l}S D \\
(p)\end{array}$ \\
\hline $\begin{array}{l}\text { Price } \\
\text { (low, medium, } \\
\text { high) }\end{array}$ & $\begin{array}{l}-0.225^{* * * *} \\
(<0.001)\end{array}$ & $\begin{array}{l}0.228^{* * * *} \\
(<0.001)\end{array}$ & $\begin{array}{l}-0.046^{* * * *} \\
(<0.001)\end{array}$ & $\begin{array}{l}0.093^{* * *} \\
(<0.001)\end{array}$ & $\begin{array}{l}-0.570^{* *} \\
(0.009)\end{array}$ & $\begin{array}{l}0.100^{* * *} \\
(<0.001)\end{array}$ & $\begin{array}{c}-0.110^{* * * *} \\
(<0.001)\end{array}$ & $\begin{array}{l}0.148^{* * * *} \\
(<0.001)\end{array}$ \\
\hline $\begin{array}{l}\text { Origin } \\
\text { (European, vs. } \\
\text { National) }\end{array}$ & $\begin{array}{l}4.061^{* * *} \\
(<0.001)\end{array}$ & $\begin{array}{l}3.021^{* * *} \\
(<0.001)\end{array}$ & $\begin{array}{l}2.918^{* * *} \\
(<0.001)\end{array}$ & $\begin{array}{l}2.284^{* * *} \\
(<0.001)\end{array}$ & $\begin{array}{l}2.638^{* * *} \\
(<0.001)\end{array}$ & $\begin{array}{l}3.117^{* * *} \\
(<0.001)\end{array}$ & $\begin{array}{l}2.156^{* * * *} \\
(<0.001)\end{array}$ & $\begin{array}{l}1.786^{* * * *} \\
(<0.001)\end{array}$ \\
\hline $\begin{array}{l}\text { Technology } \\
\text { (Air-dried, vs. } \\
\text { Microwave- } \\
\text { dried) }\end{array}$ & $\begin{array}{l}-3.537^{* * * *} \\
(<0.001)\end{array}$ & $\begin{array}{l}2.723^{* * *} \\
(<0.001)\end{array}$ & $\begin{array}{l}-3.722^{* * *} \\
(<0.001)\end{array}$ & $\begin{array}{l}2.990^{* * *} \\
(<0.001)\end{array}$ & $\begin{array}{l}-4.208^{* * * *} \\
(<0.001)\end{array}$ & $\begin{array}{l}3.518^{* * *} \\
(<0.001)\end{array}$ & $\begin{array}{l}-2.471 * * * \\
(<0.001)\end{array}$ & $\begin{array}{l}2.514^{* * * *} \\
(<0.001)\end{array}$ \\
\hline $\begin{array}{l}\text { Nutrients } \\
\text { (Natural, vs. } \\
\text { More natural) }\end{array}$ & $\begin{array}{c}0.033 \\
(0.923)\end{array}$ & $\begin{array}{l}0.933^{* *} \\
(0.003)\end{array}$ & $\begin{array}{c}0.051 \\
(0.820)\end{array}$ & $\begin{array}{l}0.707^{* *} \\
(0.001)\end{array}$ & $\begin{array}{l}-0.381 \\
(0.113)\end{array}$ & $\begin{array}{c}0.363 \\
(0.313)\end{array}$ & $\begin{array}{l}-0.141^{* *} \\
(0.007)\end{array}$ & $\begin{array}{l}0.500^{* * * *} \\
(<0.001)\end{array}$ \\
\hline $\begin{array}{l}\text { Opt-out } \\
\text { (Buy vs. No Buy) }\end{array}$ & $\begin{array}{l}-5.702^{* * *} \\
(<0.001)\end{array}$ & $\begin{array}{l}6.530^{* * *} \\
(<0.001)\end{array}$ & $\begin{array}{l}-3.553^{* * *} \\
(<0.001)\end{array}$ & $\begin{array}{l}2.892^{* * *} \\
(<0.001)\end{array}$ & $\begin{array}{l}-4.765^{* * *} \\
(<0.001)\end{array}$ & $\begin{array}{l}3.174^{* * *} \\
(<0.001)\end{array}$ & $\begin{array}{l}-2.993^{* * *} \\
(<0.001)\end{array}$ & $\begin{array}{l}2.835^{* * *} \\
(<0.001)\end{array}$ \\
\hline Price*Origin & $\begin{array}{l}-0.014 \\
(0.768)\end{array}$ & $\begin{array}{l}0.156^{* *} \\
(0.001)\end{array}$ & $\begin{array}{l}-0.057 \\
(0.065)\end{array}$ & $\begin{array}{c}0.034 \\
(0.335)\end{array}$ & $\begin{array}{l}-0.015 \\
(0.641)\end{array}$ & $\begin{array}{l}0.074^{*} \\
(0.011)\end{array}$ & $\begin{array}{c}0.012 \\
(0.299)\end{array}$ & $\begin{array}{l}0.061^{* * *} \\
(<0.001)\end{array}$ \\
\hline $\begin{array}{l}\text { Price* } \\
\text { Technology }\end{array}$ & $\begin{array}{l}0.005 \\
(0.898)\end{array}$ & $\begin{array}{c}0.009 \\
(0.867)\end{array}$ & $\begin{array}{c}0.048 \\
(0.102)\end{array}$ & $\begin{array}{l}0.109^{* * *} \\
(0.002)\end{array}$ & $\begin{array}{c}0.042 \\
(0.889)\end{array}$ & $\begin{array}{c}0.022 \\
(0.597)\end{array}$ & $\begin{array}{c}0.009 \\
(0.404)\end{array}$ & $\begin{array}{l}0.422^{*} \\
(0.021)\end{array}$ \\
\hline Price*Nutrients & $\begin{array}{l}-0.017 \\
(0.554)\end{array}$ & $\begin{array}{c}0.039 \\
(0.371)\end{array}$ & $\begin{array}{l}-0.027 \\
(0.166)\end{array}$ & $\begin{array}{l}0.080^{* * *} \\
(0.001)\end{array}$ & $\begin{array}{l}-0.007 \\
(0.715)\end{array}$ & $\begin{array}{c}0.026 \\
(0.574)\end{array}$ & $\begin{array}{c}0.002 \\
(0.783)\end{array}$ & $\begin{array}{l}0.033^{*} \\
(0.014)\end{array}$ \\
\hline $\begin{array}{l}\text { Technology* } \\
\text { Origin }\end{array}$ & $\begin{array}{l}1.934^{* * *} \\
(0.005)\end{array}$ & $\begin{array}{l}3.744^{* * *} \\
(<0.001)\end{array}$ & $\begin{array}{l}-0.561 \\
(0.209)\end{array}$ & $\begin{array}{l}2.152^{* * *} \\
(<0.001)\end{array}$ & $\begin{array}{l}-0.999^{*} \\
(0.023)\end{array}$ & $\begin{array}{c}1.255 \\
(0.051)\end{array}$ & $\begin{array}{c}0.027 \\
(0.738)\end{array}$ & $\begin{array}{l}0.387^{* *} \\
(0.007)\end{array}$ \\
\hline $\begin{array}{l}\text { Technology* } \\
\text { Nutrients }\end{array}$ & $\begin{array}{l}-0.332 \\
(0.468)\end{array}$ & $\begin{array}{l}1.900^{* * *} \\
(<0.001)\end{array}$ & $\begin{array}{l}-0.728^{*} \\
(0.041)\end{array}$ & $\begin{array}{c}0.346 \\
(0.352)\end{array}$ & $\begin{array}{l}-0.268 \\
(0.474)\end{array}$ & $\begin{array}{l}1.293^{* *} \\
(0.001)\end{array}$ & $\begin{array}{l}-0.119 \\
(0.059)\end{array}$ & $\begin{array}{c}0.018 \\
(0.932)\end{array}$ \\
\hline Nutrients* Origin & $\begin{array}{c}0.145 \\
(0.791)\end{array}$ & $\begin{array}{c}1.004 \\
(0.184)\end{array}$ & $\begin{array}{c}0.634 \\
(0.126)\end{array}$ & $\begin{array}{l}0.952^{* *} \\
(0.003)\end{array}$ & $\begin{array}{l}0.860^{*} \\
(0.036)\end{array}$ & $\begin{array}{c}0.381 \\
(0.387)\end{array}$ & $\begin{array}{c}0.027 \\
(0.703)\end{array}$ & $\begin{array}{c}0.248 \\
(0.193)\end{array}$ \\
\hline
\end{tabular}

$\mathrm{p}<0.001 ;{ }^{* *} \mathrm{p}<0.01 ;{ }^{*} \mathrm{p}<0.05$ 


\section{Highlights}

- First study to look at consumers' preferences for non-thermal processed (i.e. microwave drying) organic foods.

- Preferences for organic dried strawberries are investigated in three European countries.

- On average consumers reject microwave drying and prefer air drying.

- Producers should better inform consumers of the nutritional benefits of microwave drying. 
Which package of dried strawberries would you choose?

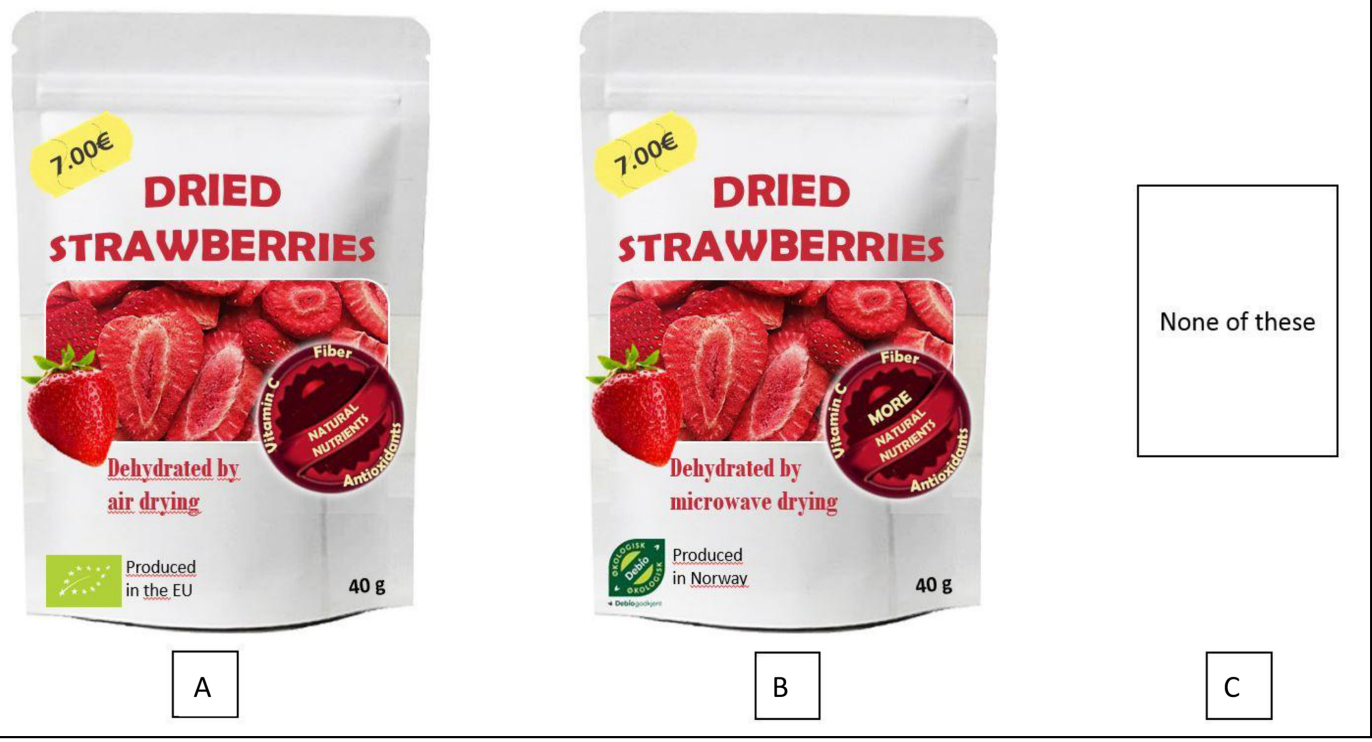

Figure 1 
NORWAY - INTERACTION EFFECT:

TECHNOLOGY *ORIGIN

$\multimap$ Air drying $\rightarrow$ Microwawe drying
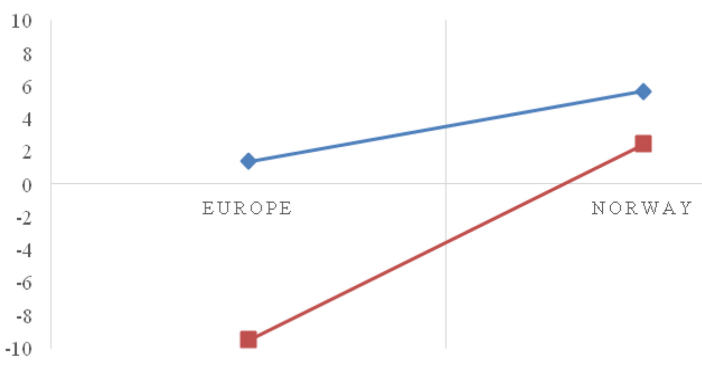

TURKEY - INTERACTION EFFECT: NUTRIENTS *ORIGIN

$\longrightarrow$ Natural nutrients $\quad \rightarrow$ More natural nutrients

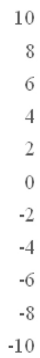

TURKEY - INTERACTION EFFECT: TECHNOLOGY * ORIGIN

$\longrightarrow$ Air drying $\rightarrow-$ Microwawe drying

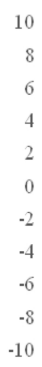

ROMANIA - INT ERACTION EFFECT: TECHNOL OGY *N UTRIENTS

$\longrightarrow$ Natural nutrients $\quad \longrightarrow$ Morenatural nutrients

10
8
6
4
2
0
-2
-4
-6
-8
-10




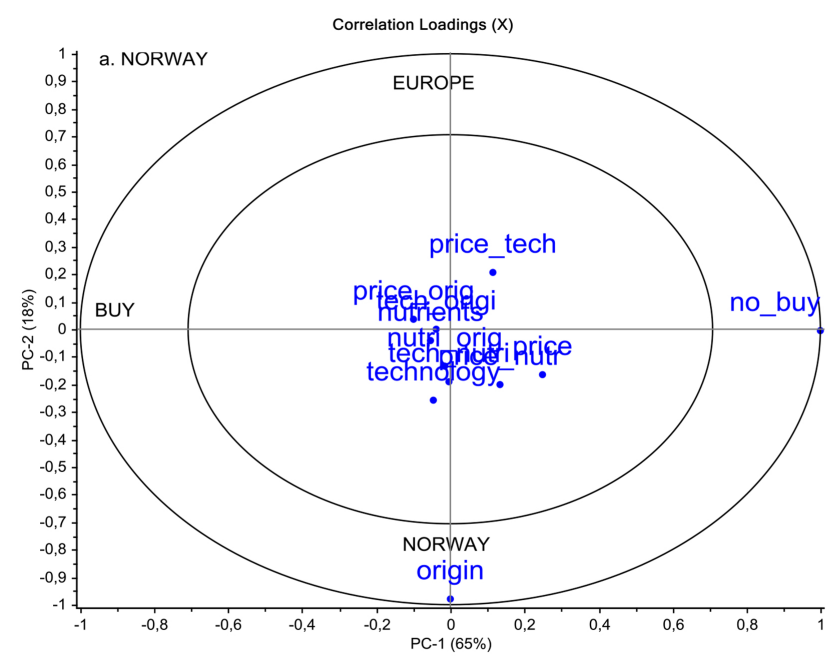

Correlation Loadings (X)
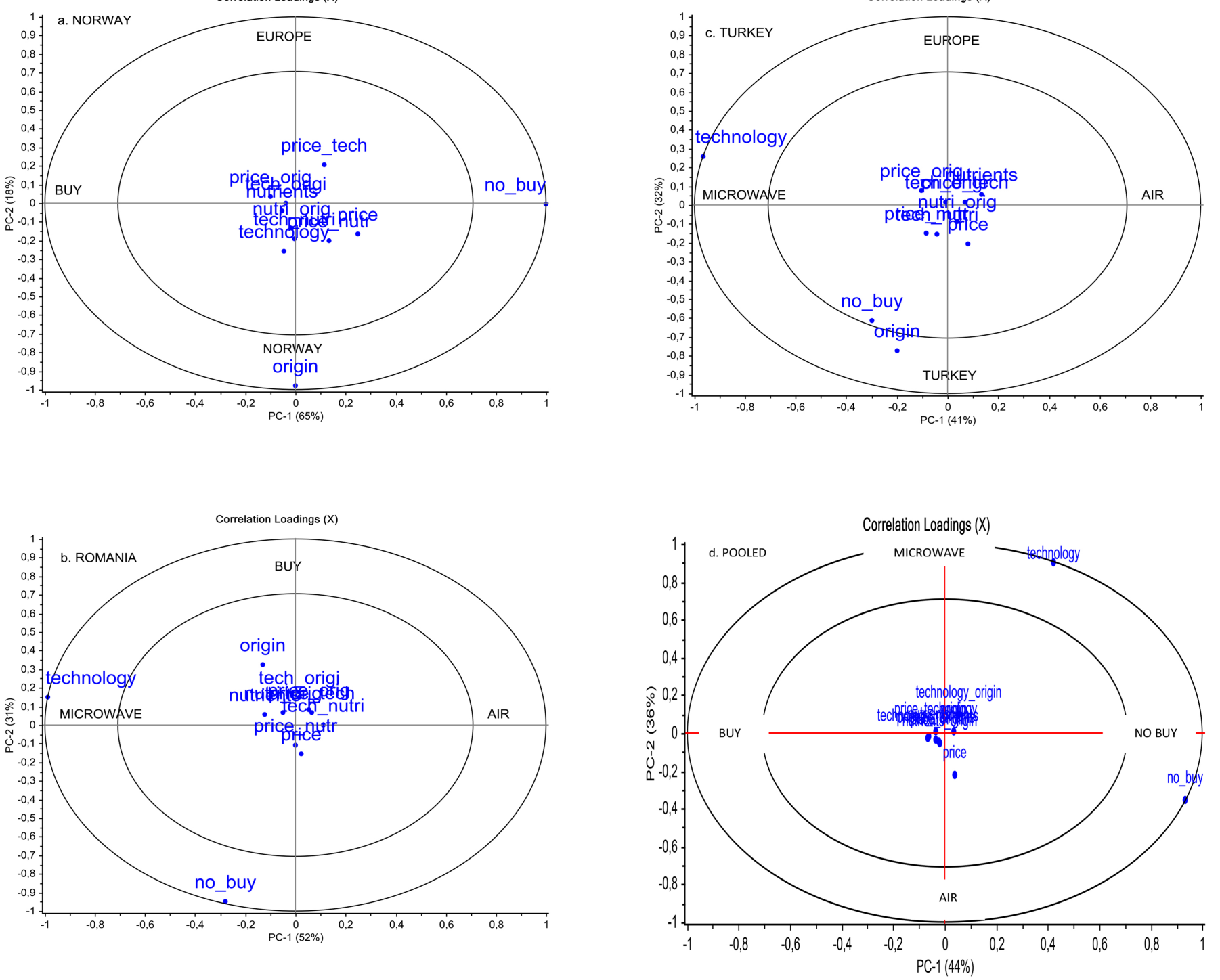

Figure 3 


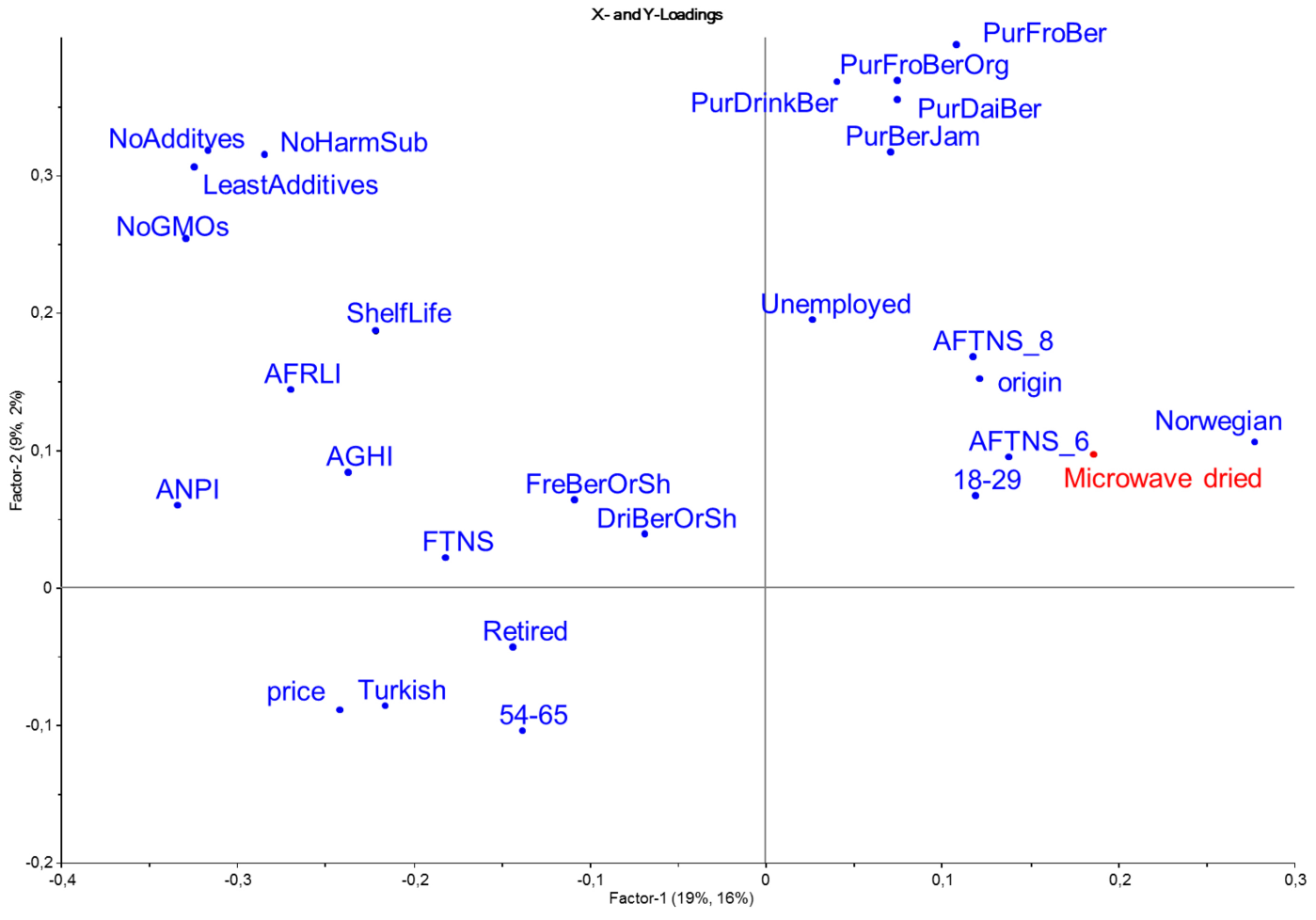

Figure 4 


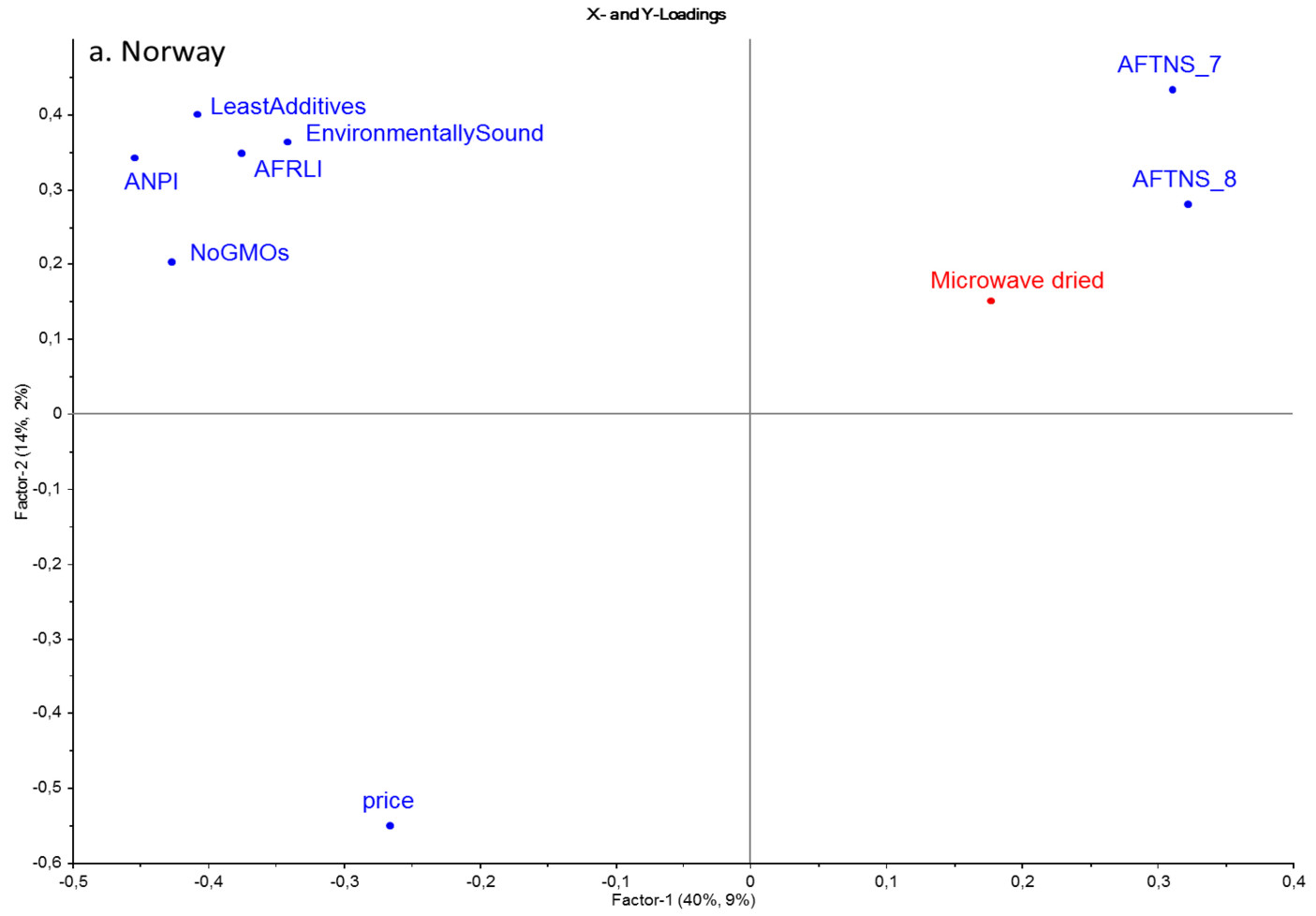

Figure 5 


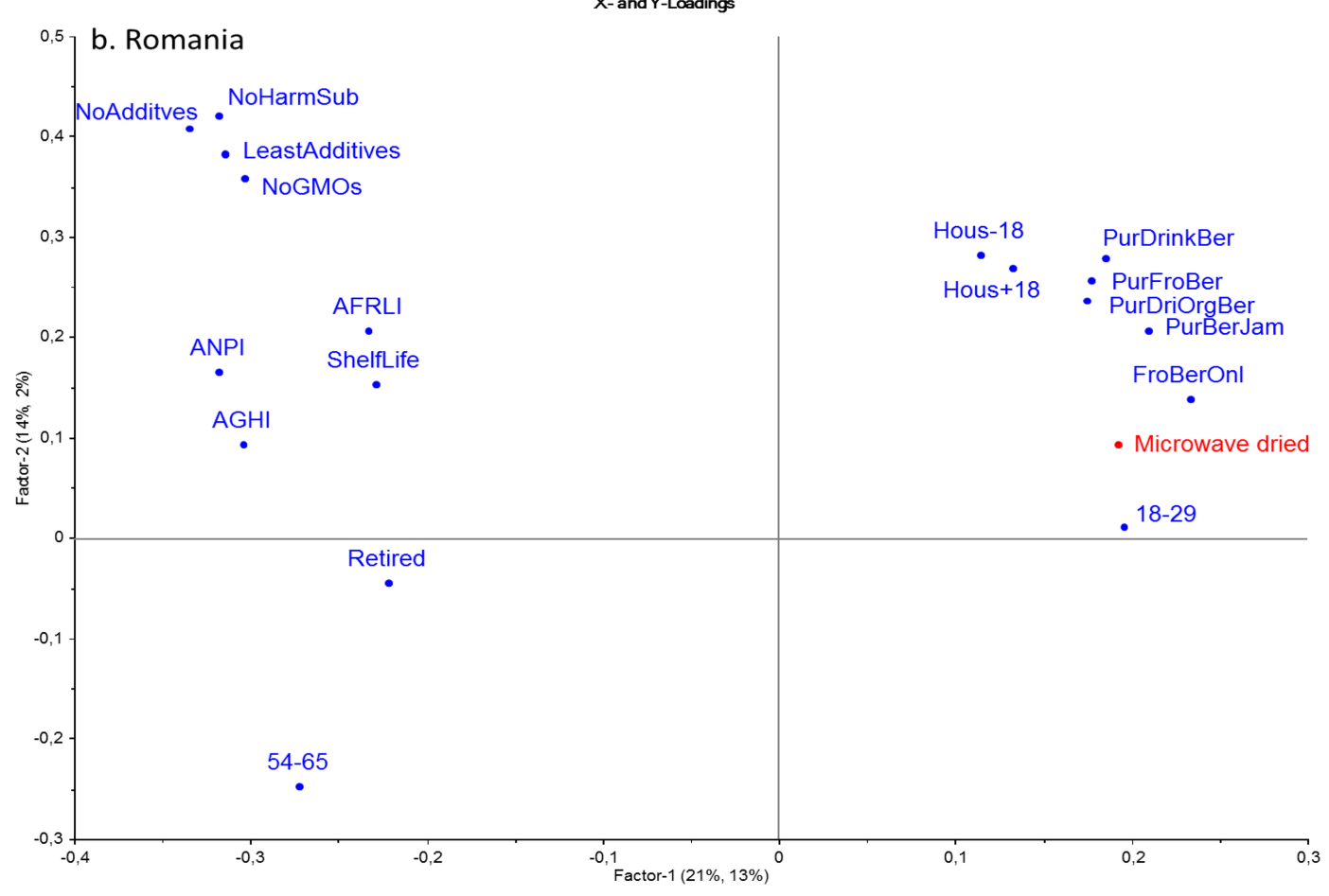

Figure 6 


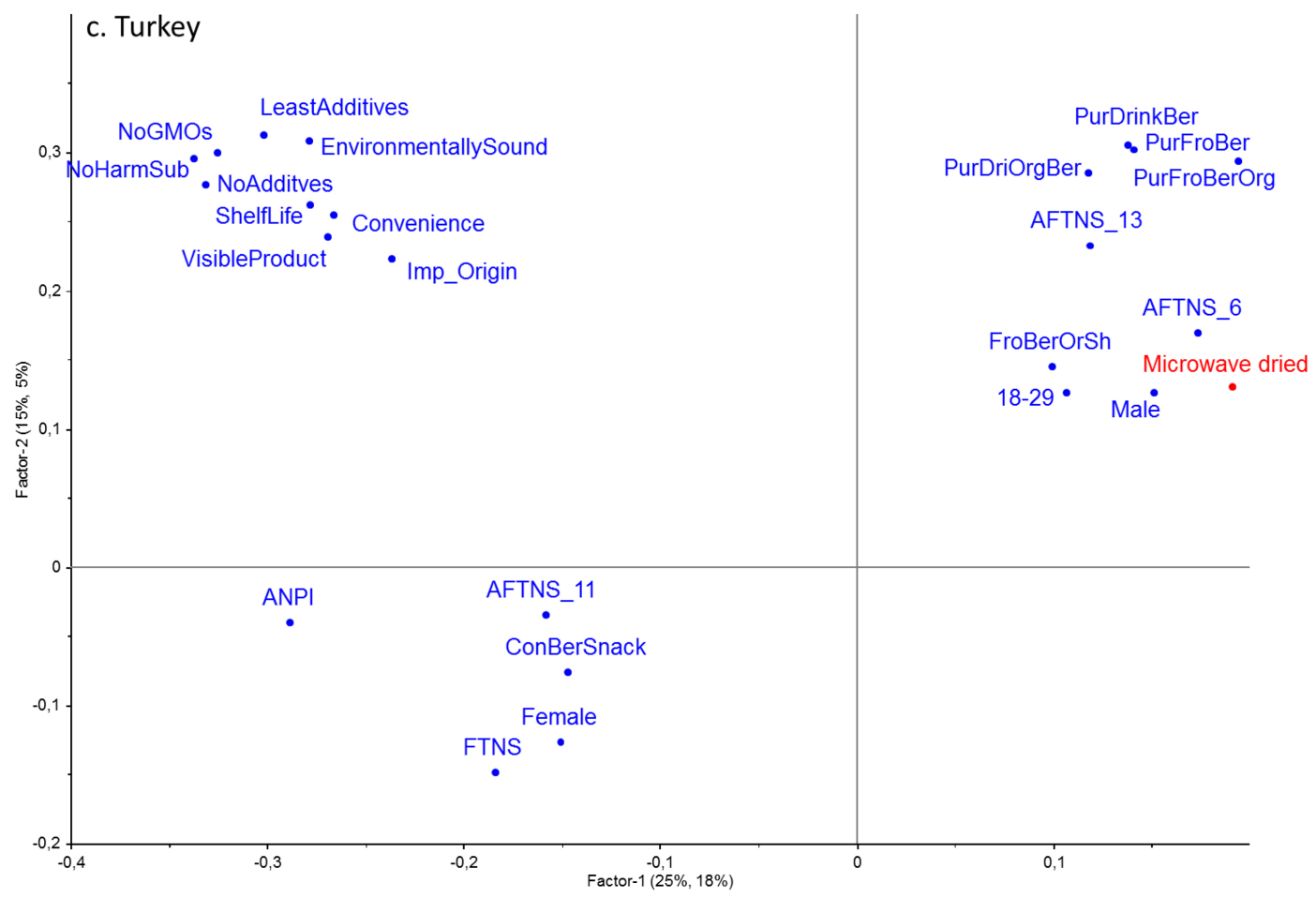

Figure 7 